\title{
Electrochemical Stability and Degradation Mechanisms of Commercial Carbon-Supported Gold Nanoparticles in Acidic Media
}

\author{
Milutin Smiljanić,* Urša Petek, Marjan Bele, Francisco Ruiz-Zepeda, Martin Šala, Primož Jovanovič, \\ Miran Gaberšcek, and Nejc Hodnik*
}

Cite This: J. Phys. Chem. C 2021, 125, 635-647

Read Online

ABSTRACT: Electrochemical stability of a commercial $\mathrm{Au} / \mathrm{C}$ catalyst in an acidic electrolyte has been investigated by an accelerated stress test (AST), which consisted of 10,000 voltammetric scans $(1 \mathrm{~V} / \mathrm{s})$ in the potential range between 0.58 and $1.41 \mathrm{~V}_{\mathrm{RHE}}$. Loss of $\mathrm{Au}$ electrochemical surface area (ESA) during the AST pointed out to the degradation of Au/C. Coupling of an electrochemical flow cell with ICP-MS showed that only a minor amount of gold is dissolved despite the substantial loss of

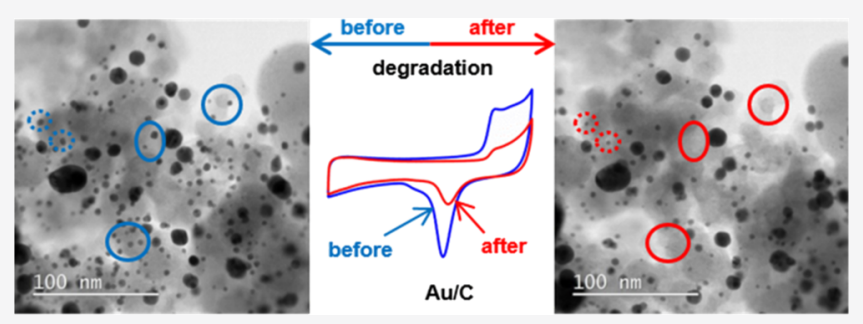
gold ESA during the AST ( $\sim 35 \%$ of initial value remains at the end of the AST). According to the electrochemical mass spectrometry experiments, carbon corrosion occurs during the AST but to a minor extent. By using identical location scanning electron microscopy and identical location transmission electron microscopy, it was possible to discern that the dissolution of small $\mathrm{Au}$ particles $(<5 \mathrm{~nm})$ within the polydisperse Au/C sample is the main degradation mechanism. The mass of such particles gives only a minor contribution to the overall Au mass of the polydisperse sample while giving a major contribution to the overall ESA, which explains a significant loss of ESA and minor loss of mass during the AST. The addition of low amounts of chloride anions $\left(10^{-4} \mathrm{M}\right)$ substantially promoted the degradation of gold nanoparticles. At an even higher concentration of chlorides $\left(10^{-2} \mathrm{M}\right)$, the dissolution of gold was rather effective, which is useful from the recycling point of view when rapid leaching of gold is desirable.

\section{INTRODUCTION}

Noble metals are irreplaceable for a variety of applications in advanced technologies due to their unique properties, such as high melting point, excellent electrical conductivity, good catalytic activity, high corrosion resistance, and biomedical compatibility. In electrochemical energy storage and conversion devices, as well as in electrochemical synthesis, noble metals are widely used catalysts in the form of nanoparticles (NPs) dispersed on high area carbon supports. For example, $\mathrm{Pt}$ NPs are a state-of-the-art catalyst for several reactions, such as oxygen reduction and hydrogen oxidation/evolution; ${ }^{1-3}$ Iroxide and $\mathrm{Ru}$-oxide are the best catalysts for oxygen evolution, ${ }^{4,5}$ while $\mathrm{Au}$ is used for electrochemical $\mathrm{CO}_{2}$ reduction $^{6-8}$ and $\mathrm{H}_{2} \mathrm{O}_{2}$ production through selective $2 \mathrm{e}^{-}$ oxygen reduction reaction. ${ }^{8-12}$ Besides activity, a suitable catalyst must provide long term durability and stable running of the given electrochemical process to fulfill the basic demands for commercial applicability, so it is necessary to understand electrochemically induced dissolution and other structural changes of noble metals. Widespread usage of Pt in electrocatalysis has led to a well-studied electrochemical dissolution of bulk Pt electrodes ${ }^{13-15}$ and carbon-supported Pt NPs. ${ }^{16-21}$ These studies showed that degradation and hence the loss of electrochemical surface area (ESA) of Pt catalysts is a complex process that can proceed via several mechanisms, such as particle size growth, dissolution, Ostwald ripening, detachment of the particles, and loss of the electrical contact. $^{17,20,21}$ It has also been pointed out that $\mathrm{Pt}$ is particularly sensitive to the transition between the oxidized and reduced state of the surface (which corresponds to the start/stop conditions in fuel cells) rather than to the potentiostatic exposure to high potentials.

Since gold is also widely used in electrochemical applications, ${ }^{8}$ the electrochemical dissolution of bulk gold electrodes is of great interest. Recently, this issue has been studied in detail by Cherevko and colleagues. ${ }^{22-26}$ It was shown that like $\mathrm{Pt}$, bulk $\mathrm{Au}$ also dissolves via a transient dissolution mechanism up to an upper potential limit (UPL) of $\sim 1.60 \mathrm{~V}_{\mathrm{RHE}}$, while direct anodic dissolution starts to prevail as the main dissolution pathway at UPLs above $1.60 \mathrm{~V}_{\mathrm{RHE}}$. Surprisingly, only a few studies have been conducted to test the electrochemical stability of the Au NPs. ${ }^{27-30}$ Few of these works have focused on showing that the structures consisting

Received: November 6, 2020

Revised: December 28, 2020

Published: January 6, 2021 
of a capping-agent stabilized Au particles or Au NPs attached to tether layers covalently bonded to a conductive substrate are stable in a similar potential window as bulk gold electrodes, but there was no information about the intrinsic electrochemical stability of Au NPs. ${ }^{27,28}$ Jovanovic et al. pointed out that the dissolution mechanism of bulk and nanoparticulate Au samples can differ due to different structures of the electrode/ electrolyte layer and that NPs can exhibit even higher corrosion resistance than the bulk counterpart. ${ }^{29}$ In a study conducted by Steven et al., the stability of carbon-supported $\mathrm{Au}$ NPs with a narrow size range between 0.8 and $4.5 \mathrm{~nm}$ was probed by 100 voltammetric scans in $0.5 \mathrm{M} \mathrm{H}_{2} \mathrm{SO}_{4}$ in the potential range between 0 and $1.35 \mathrm{~V}(v \mathrm{sg} / \mathrm{AgCl}),{ }^{30}$ which is the potential range commonly used for the cleaning or activation of gold electrodes. The stability of gold NPs was found to be size-dependent, as a loss of gold ESA was observed for samples containing smaller particles (below $3 \mathrm{~nm}$ ) but not for larger ones $(4.5 \mathrm{~nm})$. Growth of the particles has been observed upon cycling, which means that under the conditions applied in this work, the dissolution of gold followed by redeposition onto the existing gold particles (i.e. Ostwald ripening) was the main degradation mechanism. ${ }^{30}$

The accelerated stress test (AST) is adopted as an expedient method to screen the stability of electrocatalysts deposited in the form of thin films on rotating disc electrodes (RDEs). Since Pt NPs are used as catalysts in fuel cells, different ASTs have been performed by potentiostatic or potentiodynamic treatment with continuous monitoring of the decrease in the ESA. ${ }^{18,19,31-33}$ ESA monitoring provides information about the loss of catalyst activity due to the loss of the effective metallic surface area, but it does not reveal the nature of the underlying degradation mechanism(s). A deeper insight into different degradation mechanisms requires the use of advanced characterization techniques, such as identical location scanning electron microscopy (IL-SEM), ${ }^{18,19}$ identical location transmission electron microscopy (IL-TEM), ${ }^{16,17,34,35}$ on-line monitoring of dissolution, ${ }^{36,37}$ and gas evolution. ${ }^{38,39}$ In the case of Pt catalysts, it has been shown that degradation can occur through several mechanisms that can take place concurrently, including particle detachment, a dissolution that can be followed by redeposition on the existing larger particles (i.e. Ostwald ripening), coalescence, and carbon corrosion. ${ }^{20,34}$ Interestingly, in the case of Au NPs, there is a lack of AST in the literature even though Au NPs are widely used in electrocatalysis. $^{6-12}$ They can also be applicable in fuel cells since the addition of gold increases the stability of $\mathrm{Pt}$ during oxygen reduction. ${ }^{39-41}$ With that in mind, the AST performed solely for Au NPs would provide a benchmark and shed some light on their long-term stability and possible usage as durable electrocatalysts, for instance, for hydrogen peroxide production or carbon dioxide reduction. ${ }^{6-12}$

In this work, we present an in-depth study of the stability of commercial carbon-supported polydisperse gold NPs by subjecting them to AST consisting of 10,000 fast voltammetric scans in the $0.05 \mathrm{M} \mathrm{H}_{2} \mathrm{SO}_{4}$ electrolyte in the potential range between 0.58 and $1.41 \mathrm{~V}$ versus the RHE. At a UPL of 1.41 $\mathrm{V}_{\mathrm{RHE}}$, gold oxidation takes place, while a lower potential limit (LPL) of $0.58 \mathrm{~V}_{\mathrm{RHE}}$ provides a full reduction of the previously formed gold oxide. The first reason for choosing this particular UPL is the fact that a similar UPL of around $1.40 \mathrm{~V}_{\mathrm{RHE}}$ has been commonly used when testing the electrochemical stability and degradation of $\mathrm{Pt}$ catalysts ${ }^{18,19}$ since similar potentials can be reached in fuel cells during start-up/shut down events. The second reason is that the understanding of the stability of gold samples in electrochemical environments with an UPL close to $1.40 \mathrm{~V}_{\mathrm{RHE}}$ has a potential application for the (electro)chemical recycling of gold. Namely, Hodnik and colleagues have used accumulated knowledge about Pt (in)stability to develop a green electrochemical method for Pt recycling. ${ }^{42}$ Transient $\mathrm{Pt}$ dissolution was induced by repetitive switching between oxidative and reductive potentials on the $\mathrm{Pt}$ surface by the alternative exposure to oxidative and reductive gasses, respectively. In this way, transient Pt dissolution was mimicked without the use of an external potential controlling device. Moreover, Pt dissolution was achieved with high leaching yields under quite mild conditions with respect to the currently used pyro- or hydrometallurgical processes. Therefore, it would be appealing to extend this promising approach based on gasinduced transient dissolution for recycling of $\mathrm{Au}$ as well. Our preliminary results have shown that an open circuit potential of $1.41 \mathrm{~V}_{\mathrm{RHE}}$ has been established when gold NPs were exposed to ozone-saturated $0.05 \mathrm{M} \mathrm{H}_{2} \mathrm{SO}_{4}$, and therefore, using this UPL will also provide the first insights about the viability of the approach developed by Hodnik ${ }^{42}$ for recycling of gold. Chloride ions are a common impurity in electrochemical environments that can cause accelerated degradation of the catalysts, ${ }^{25,29}$ which is certainly undesirable in energy storage and conversion devices. On the other hand, accelerated dissolution of gold in the presence of chlorides is necessary for recycling procedures, as described for $\mathrm{Pt}$ in ref 42 . Therefore, performing the AST with an UPL of $1.41 \mathrm{~V}_{\mathrm{RHE}}$ in the electrolyte with and without the presence of chloride ions provides an insight into the stability and degradation mechanisms of the Au NPs in the presence of impurities, while also testing if the approach by Hodnik and colleagues ${ }^{42}$ could be beneficial for recycling of gold. An essential tool for studying Au dissolution is analyzing its concentration in a constant flow of electrolyte through an electrochemical flow cell (EFC) coupled with an ICP-MS detector (EFC-ICPMS). ${ }^{29,43,44}$ Using the EFC-ICP-MS setup, the dissolution mechanism of the gold NPs will be assessed as well as the influence of the chlorides on the degradation of the gold catalyst. The electrochemical mass spectrometry (EC-MS) setup is a powerful tool for studying gas evolution during electrochemical reactions, which will show if carbon corrosion contributes to the overall degradation of the $\mathrm{Au} / \mathrm{C}$ catalyst during the AST. To unambiguously unravel the degradation mechanism responsible for the loss of gold ESA observed during the AST, sequential IL-SEM imaging was performed both in the presence and in the absence of chlorides, while ILTEM imaging was performed before and after AST in the neat $0.05 \mathrm{M} \mathrm{H}_{2} \mathrm{SO}_{4}$ electrolyte.

\section{METHODS}

Commercial Au/C NPs supported on Vulcan XC-72 (Fuel Cell Store) with $20 \%$ gold on carbon were used for degradation studies. A catalyst ink was prepared by mixing 5 $\mathrm{mg}$ of $\mathrm{Au} / \mathrm{C}$ powder with $3 \mathrm{~mL}$ of a solvent consisting of Milli$\mathrm{Q}$ water (25 vol \%), isopropanol (75 vol \%), and $50 \mu \mathrm{L}$ of Nafion. Glassy carbon (GC) discs (HTW, $5 \mathrm{~mm}$ diameter) in a poly(tetrafluoroethylene) shroud were used as working RDEs. They were prepared by hand-polishing using $0.05 \mu \mathrm{m}$ alumina paste followed by sonication in Milli-Q water to remove alumina residues. To prepare reproducible and homogeneous thin films, a RDE was mounted on a reversed rotator and $20 \mu \mathrm{L}$ of the catalyst ink was dropcast on the GC 
disc. Then, the rotation was slowly increased up to $700 \mathrm{rpm}$ and left for 30 min until the films have dried.

Electrochemical measurements were conducted in a threeelectrode setup, with an Au/C-modified GC electrode, double junction $\mathrm{Ag} / \mathrm{AgCl}$ electrode, and a graphite rod as the working, reference, and counter electrodes, respectively. Using a double junction $\mathrm{Ag} / \mathrm{AgCl}$ reference electrode minimized the possibility of electrolyte contamination by leakage of chlorides, which was especially important for long AST measurements. All the potentials in this work are referred versus the RHE. The graphite counter electrode was placed in a separate compartment to exclude the possibility of deposition of the dissolved $\mathrm{Au}$ particles from the working electrode during the AST. Before each measurement, the glass electrochemical cell was boiled in deionized water for at least $1 \mathrm{~h}$ to ensure clean conditions. Electrochemical measurements were conducted in a $0.05 \mathrm{M} \mathrm{H}_{2} \mathrm{SO}_{4}$ electrolyte prepared from Suprapur sulfuric acid (Merck) and diluted by Milli-Q water. Before AST, Au/C films were electrochemically activated by 20 voltammetric scans $(100 \mathrm{mV} / \mathrm{s})$ in the potential range between -0.02 and $1.63 \mathrm{~V}_{\mathrm{RHE}}$ in a $0.05 \mathrm{M} \mathrm{H}_{2} \mathrm{SO}_{4}$ electrolyte, which provided a stable voltammetric response as the baseline for degradation studies. After activation, the AST was applied, consisting of 10,000 fast scans $(1 \mathrm{~V} / \mathrm{s})$ in the potential range between 0.58 and $1.41 \mathrm{~V}_{\mathrm{RHE}}$. At the beginning of the AST and after every set of 500 scans during the AST, two slower cyclic voltammograms (CVs) with a scan rate of $100 \mathrm{mV} / \mathrm{s}$ were recorded with a higher UPL of $1.58 \mathrm{~V}_{\mathrm{RHE}}$ in order to follow the loss of the ESA by integrating the more developed Au-oxide reduction peak. In the case of the $0.05 \mathrm{M} \mathrm{H}_{2} \mathrm{SO}_{4}+10^{-4} \mathrm{M} \mathrm{Cl}^{-}$ electrolyte, CVs for tracking ESA were collected in the same electrolyte since such concentration of chlorides does not significantly influence Au oxidation/reduction processes as the values within the calculation error were obtained with respect to the chloride-free electrolyte. However, when the concentration of chlorides was set to $10^{-2} \mathrm{M}, \mathrm{CVs}$ for gold ESA tracking were recorded in the chloride-free electrolyte due to a large suppression of gold oxidation/reduction in the presence of an increased amount of $\mathrm{Cl}^{-}$. We note that in all cases, recording of $42 \mathrm{CVs}$ with a higher UPL for the sake of ESA monitoring may lead to some additional dissolution of Au NPs, but this contribution is likely negligible with respect to the 10,000 fast scans applied in the AST procedure. The ASTs were conducted in $0.05 \mathrm{M} \mathrm{H}_{2} \mathrm{SO}_{4}$ without and with the presence of $10^{-4}$ and $10^{-2} \mathrm{M}$ chlorides, which were introduced in the electrolyte through the addition of the appropriate amounts of $\mathrm{HCl}$ (analytical grade, Merck). In all cases, the electrolyte volume was kept constant at $70 \mathrm{~mL}$. During the activation and AST, the working electrode was rotated at 1600 rpm. Activation and ASTs were performed on a Nordic ECi 211 potentiostat (Nordic Electrochemistry) with no Ohmic drop compensation and a potential step of $1 \mathrm{mV}$.

The X-ray diffraction (XRD) analysis was carried out with a Siemens D5000 instrument with a $\mathrm{Cu} K \alpha 1$ radiation $(\lambda=$ $1.5406 \AA$ ) in the $2 \theta$ range from 10 to $60^{\circ}$ with a $0.04^{\circ}$ step per $1 \mathrm{~s}$. IL-SEM experiments were performed on a field-emission scanning electron microscope (Supra 35 VP, Carl Zeiss, Germany). A GC RDE with a catalyst film was mounted directly onto the SEM stage with a special home-made holder and imaged on the same locations before, during, and at the end of the AST. Characterization of Au NPs and tracking of the AST-induced changes were performed also by scanning transmission electron microscopy (STEM) imaging (JEOL
JEM-ARM200CF Ltd., Tokyo, Japan) operated at $80 \mathrm{kV}$. ILTEM imaging was performed on a gold TEM finder grid coated with the $\mathrm{Au} / \mathrm{C}$ catalyst film (200 mesh Plano $\mathrm{GmbH}$ ). $5 \mu \mathrm{L}$ of the catalyst ink was deposited on a TEM grid and dried under ambient conditions. In this experiment, the working electrode consisted of a TEM grid, coated with the sample, mounted onto a GC RDE, and tightened against it with a special home-made Teflon cap to ensure good contact. The AST was then performed under the same conditions and in the same setup as described above. The grid was imaged by TEM on the same locations before and at the end of the AST in the neat $0.05 \mathrm{M} \mathrm{H}_{2} \mathrm{SO}_{4}$.

The EFC-ICP-MS system for dissolved metal analysis was made of an EFC that was connected to an ICP-MS instrument (Agilent 7500ce, Agilent Technologies), as described in detail in our previous works. ${ }^{29,43,44}$ ICP-MS was equipped with a MicroMist glass concentric nebulizer and a Peltier cooled Scott-type double-pass quartz spray chamber. The forward radio frequency power was set to $1500 \mathrm{~W}$, and the Ar gas flows were as follows: carrier, $0.85 \mathrm{~L} / \mathrm{min}$; makeup, $0.28 \mathrm{~L} / \mathrm{min}$; plasma, $1 \mathrm{~L} / \mathrm{min}$; and cooling, $15 \mathrm{~L} / \mathrm{min}$. The standardization curve was determined based on the standard solutions containing $1,2,5,10,20,50$, and $100 \mathrm{ppb}$ of Au. The EFC was custom-made from polyether ether ketone (PEEK) based on a design of a commercial cell (cross-flow cell, BASi). The electrolyte flew in the direction from the counter electrode to the working electrode at a constant flow of $400 \mu \mathrm{L} / \mathrm{min}$ with a mechanic syringe pump. A $1.0 \mathrm{~mm}$ thick homemade silicon gasket with an oval-shaped opening of $1.5 \mathrm{~cm}^{2}$ was set the cell volume. GC discs (3 $\mathrm{mm}$ diameter) embedded into the PEEK material (ALS dual-type electrode for cross-flow cell, $25 \times 25$ $\mathrm{mm}^{2}$ ) were used as the working and counter electrode. They were polished with a $0.05 \mu \mathrm{m} \mathrm{Al}_{2} \mathrm{O}_{3}$ polishing paste and cleaned in Milli-Q in an ultrasonic bath. The catalyst ink (5 $\mu \mathrm{L}$ ) was deposited on one of the GC disks and dried under ambient conditions, partially covered to slow down solvent evaporation for better film quality and to prevent deposition of impurities. $\mathrm{An} \mathrm{Ag} / \mathrm{AgCl}$ reference electrode with a ceramic frit (MW-2030, BASi) was used to complete the standard threeelectrode setup, and its potential was determined versus a RHE. A BioLogic SP-200 potentiostat was used for electrochemical experiments with a $1 \mathrm{~mA}$ current range, $160 \mathrm{kHz}$ bandwidth, and no Ohmic drop compensation.

To test for carbon support oxidation, $\mathrm{CO}_{2}$ release was monitored in an electrochemical mass spectrometry (EC-MS) setup (SpectroInlets), as described in detail elsewhere. ${ }^{45,46}$ Briefly, the material ( $5 \mu \mathrm{L}$ of the ink) was deposited on a GC disk (Pine, $5 \mathrm{~mm}$ diameter) and positioned in parallel to a porous interface to a mass spectrometer at a distance of 100 $\mu \mathrm{m}$. All the electrochemically produced volatile species could thus diffuse through the layer of the electrolyte and then be analyzed by the MS as a function of applied potential. The electrochemical cell, assembled on the chip, was a standard three-electrode cell. $\mathrm{An} \mathrm{Ag} / \mathrm{AgCl}$ reference and a graphite rod counter electrode were used and connected to an SP-300 potentiostat (BioLogic). The experiments were performed without Ohmic drop compensation and with the bandwidth factor set to 1 in the current range of $100 \mu \mathrm{A}$.

\section{RESULTS AND DISCUSSION}

3.1. Characterization of the Au/C Catalyst. The commercial catalyst used in this work was a $20 \% \mathrm{Au} / \mathrm{C}$ catalyst purchased from the Fuel Cell Store. Before proceeding 

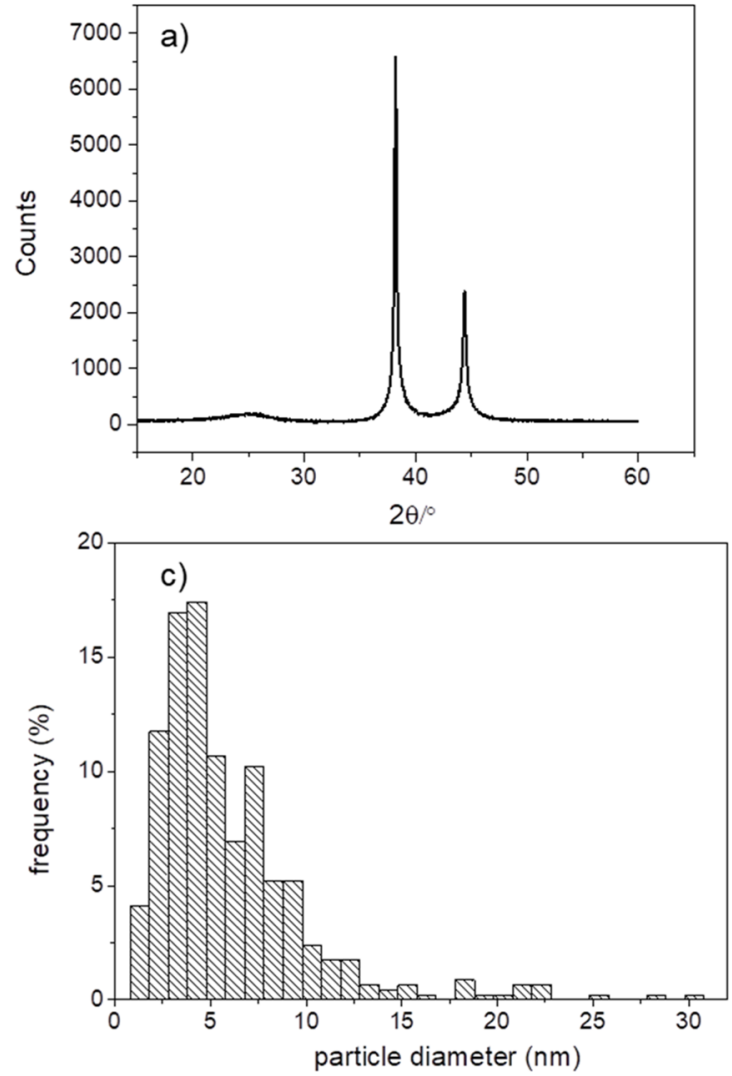
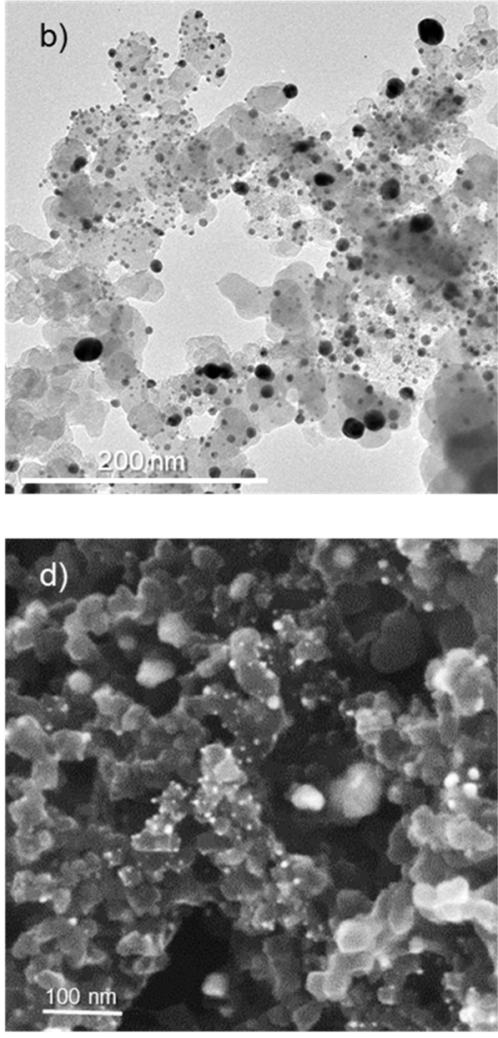

Figure 1. (a) XRD pattern of the Au/C catalyst powder; (b) TEM image of the Au/C catalyst; (c) PSD obtained by taking into account 460 particles from 14 TEM images; (d) SEM image of the Au/C catalyst film deposited on GC RDE.

to the stability studies, the catalyst had been thoroughly characterized, as depicted in Figure 1. The XRD pattern of the $\mathrm{Au} / \mathrm{C}$ powder (Figure 1a) contains diffraction peaks at 38.2 and $44.4^{\circ}$ related to the (111) and (200) reflections of the face centered cubic Au phase with a $F m 3 m$ space group (JCPDS 00-001-1172). Figure $1 \mathrm{~b}$ shows a TEM image of the pristine $\mathrm{Au} / \mathrm{C}$ sample, where one can see spherical $\mathrm{Au}$ NPs that are well-distributed over the carbon support, polydisperse in size, and mainly much smaller than $20-30 \mathrm{~nm}$, that is, the reported average size by the manufacturer. The corresponding particle size distribution (PSD) (Figure 1c) shows that the majority of particle diameters are smaller than $10 \mathrm{~nm}$ (around 90\%), while only a minor share of the particles is larger than $20 \mathrm{~nm}$. On some investigated locations, notably larger $\mathrm{Au}$ particles and agglomerates were observed (up to $100 \mathrm{~nm}$, Figure S1) but due to their very low number and large size (as compared to the size of the investigated sample area), it is impossible to include them in the PSD in a way that would reliably reflect the composition of the sample. For that reason, only particles smaller than $30 \mathrm{~nm}$ were included in the PSD analysis, although the presence of large particles and aggregates should not be overlooked when interpreting the dissolution behavior. SEM imaging given in Figure 1d was performed on a thin catalyst film dried on a GC RDE. Expectedly, it shows similar features to those observed by TEM (Figure 1b). In accordance with TEM imaging, some larger particles and agglomerates were observed in different locations randomly across the sample. While polydispersity of the particle sizes makes any stability behavior more difficult to interpret, it is precisely the degradation of such realistic materials that needs to be studied for a better understanding of practical systems where degradation of Au NPs of different sizes occurs simultaneously.

Before evaluating their electrochemical properties, both bulk gold electrodes as well as $\mathrm{Au} / \mathrm{C}$ catalyst films are subjected to a so-called activation protocol in order to achieve a stable voltammetric response. The activation consists of cycling in an appropriate potential range to remove any possible surface impurities and/or left-overs from the synthesis and to allow full wetting of the catalyst layer. Bulk gold electrodes are usually pretreated by cycling up to the potential region of gold oxidation with the UPL close to the Burshtein minimum, which is just before the onset of oxygen evolution $(\sim 1.70$ $\left.\mathrm{V}_{\mathrm{RHE}}\right)^{22,23,47}$ Since at such high potentials, gold undergoes dissolution, $^{22,23}$ the $\mathrm{Au} / \mathrm{C}$ catalyst film must be activated in such a way that a stable electrochemical response is achieved without changing the properties of gold NPs and corroding the catalyst, which is pointed out in the work of Steven and colleagues. ${ }^{30}$ Several protocols were tested for the activation in $0.05 \mathrm{M} \mathrm{H}_{2} \mathrm{SO}_{4}$, and the UPL of $1.63 \mathrm{~V}_{\mathrm{RHE}}$ was found to be the optimal choice for our case since a stable voltammetric response was reached after merely $20 \mathrm{CV}$ scans (at $100 \mathrm{mV} / \mathrm{s}$ ). Even though this particular UPL does not match the potential at which a full monolayer of gold oxide is formed (which is necessary for an accurate ESA determination), the integrated oxide reduction charge can be correlated with the trend of the evolution of $\mathrm{Au}$ ESA during activation. Figure 2 presents the first, tenth, and the last (20th) voltammetric scan during the activation of the $\mathrm{Au} / \mathrm{C}$ catalyst. All the features of gold are clearly visible on the voltammograms, including the doublelayer region followed by the gold oxide formation, which commences at $\sim 1.30 \mathrm{~V}_{\mathrm{RHE}}$, and its counterpart in the backward 


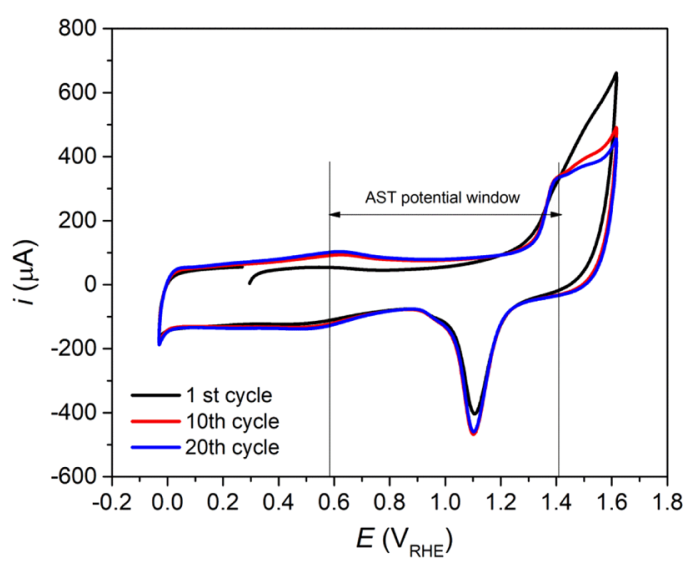

Figure 2. Activation of the $\mathrm{Au} / \mathrm{C}$ films by 20 voltammetric scans (100 $\mathrm{mV} / \mathrm{s}$ ) in $0.05 \mathrm{M} \mathrm{H}_{2} \mathrm{SO}_{4}$ in the potential range between -0.02 and $1.63 \mathrm{~V}_{\mathrm{RHE}}$. The potential window used for the AST is indicated in the graph.

scan corresponding to gold oxide reduction in the potential region between $\sim 1.35$ and $\sim 0.9 \mathrm{~V}_{\mathrm{RHE}}$. The charge due to gold oxide reduction initially increases, then slightly fluctuates, and finally reaches a stable value (see Figure S2). The increase of the ESA of gold NPs has been shown to originate mainly from the improved wetting of the catalyst layer, while further minor fluctuations can come from the restructuring of gold NPs. ${ }^{30}$ The difference between the final stable value and the highest observed value for the gold oxide reduction charge during activation (which was not reproducible) is around $3.5 \%$, while the difference between the initial and the final value is almost $10 \%$. A stable response was also achieved in the EFC-ICP-MS setup using a similar ( 0.28 to $1.58 \mathrm{~V}_{\mathrm{RHE}}, 20$ cycles, $100 \mathrm{mV} / \mathrm{s}$ ) activation protocol.

We found that within 20 cycles, the dissolution profile stabilized and that about $0.35 \pm 0.05 \%$ of the total Au mass (average of four experiments) was dissolved during the activation protocol. It is important to note that the selected activation procedure is far less aggressive than the cleaning procedures commonly used in the literature for bulk gold gld $^{22,3}$ and that it contains fewer cycles than those used in the study of Steven et al., ${ }^{30}$ where the growth of small Au NPs (up to 4.5 $\mathrm{nm}$ ) was only observed after 100 voltammetric scans in a similar potential range. While some material stress is unavoidable, activation-induced changes in the catalyst structure and its dissolution can be regarded as minimal, and more importantly, controllable and reproducible. The applied activation appears to be a suitable and quick pathway to reach a reproducible state as the baseline for the degradation studies.

3.2. Accelerated Stress Test. The AST protocol applied to study the $\mathrm{Au} / \mathrm{C}$ degradation included 10,000 fast scans (1 $\mathrm{V} / \mathrm{s}$ ) in the potential region between 0.58 and $1.41 \mathrm{~V}_{\mathrm{RHE}}$. The selected potential limits for AST are indicated in Figure 2. It can be seen that gold oxidation occurs at UPL of $1.41 \mathrm{~V}_{\mathrm{RHE}}$ but without going deep into the bulk of the phase, while in the backward scan an LPL of $0.58 \mathrm{~V}_{\mathrm{RHE}}$ ensures a full reduction of the formed gold oxide. According to the works by Cherevko and colleagues, the onset of the dissolution of gold from bulk electrodes coincides with the onset of surface oxidation, which takes place at $\sim 1.30 \mathrm{~V}_{\mathrm{RHE}} \cdot{ }^{22-26} \mathrm{Up}$ to a UPL of around 1.60 $\mathrm{V}_{\mathrm{RHE}}$, the dissolution of bulk gold electrodes occurs mainly during the reduction of gold oxide. Therefore, the potential limits applied for the AST are expected to lead to the transient dissolution of $\mathrm{Au} / \mathrm{C}$ NPs.

The degradation-induced changes were monitored in two ways: first by following the loss of the gold surface through the ESA in an RDE setup and second by recording the mass of dissolved gold in the electrolyte in the flow cell system. While the loss of the gold surface is of paramount importance in an electrocatalytic application, the dissolution process is more important from the perspective of gold dissolution for recycling applications. Figure 3 presents the results of the

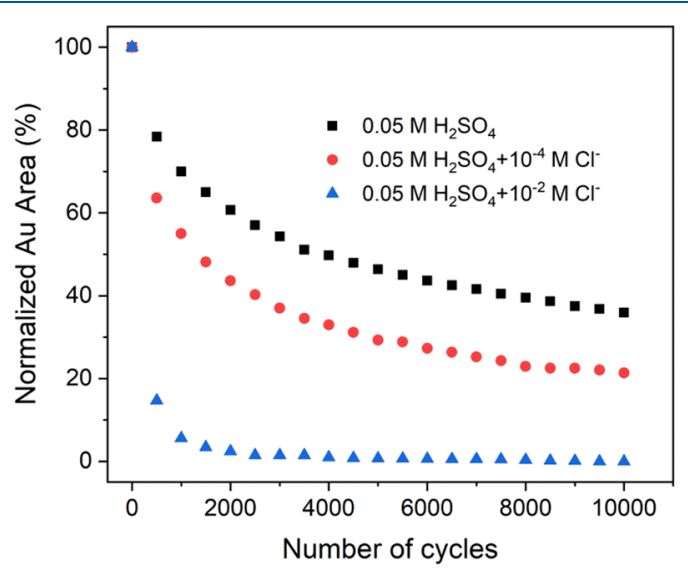

Figure 3. AST for the $\mathrm{Au} / \mathrm{C}$ catalyst conducted in $0.05 \mathrm{M} \mathrm{H}_{2} \mathrm{SO}_{4}$, $0.05 \mathrm{M} \mathrm{H}_{2} \mathrm{SO}_{4}+10^{-4} \mathrm{M} \mathrm{Cl}^{-}$and $0.05 \mathrm{M} \mathrm{H}_{2} \mathrm{SO}_{4}+10^{-2} \mathrm{M} \mathrm{Cl}^{-}$. The AST included 10,000 scans at $1 \mathrm{~V} / \mathrm{s}$ in the potential window between 0.58 and $1.41 \mathrm{~V}_{\mathrm{RHE}}$.

AST for carbon-supported Au NPs obtained in the RDE setup in acidic media expressed as the loss of the gold oxide reduction charge (which correlates with the loss of ESA), while representative sets of voltammograms used for tracking of the gold ESA decay taken during ASTs are given in Figure S3. It can be seen that significant degradation of carbon-supported $\mathrm{Au}$ NPs occurs both in the presence and in the absence of chloride ions.

In the neat $0.05 \mathrm{M} \mathrm{H}_{2} \mathrm{SO}_{4}$ electrolyte, the charge corresponding to the reduction of gold oxide is gradually decreasing and at the end of the AST, it drops down to $~ 35 \%$ of the initial value. As expected, in the presence of $10^{-4} \mathrm{M}$ chloride anions, this loss is more pronounced and drops down to $\sim 20 \%$ of the initial value. With a further increase of the concentration of chlorides to $10^{-2} \mathrm{M}$, a significant decay of the gold response is obtained at the very beginning of the AST as only $15 \%$ of the gold oxide reduction charge remains after the first 500 scans. This value rapidly drops down to below $1 \%$ after 4000 cycles, making further visualization and quantification of gold features practically impossible.

Over the first 500 fast scans in the neat $0.05 \mathrm{M} \mathrm{H}_{2} \mathrm{SO}_{4}$, a significant loss of the Au ESA of around $22 \%$ is observed, which could be surprising when taking into account that a UPL of $1.41 \mathrm{~V}_{\mathrm{RHE}}$ is not particularly a high anodic potential limit. Loss of the gold oxide reduction charge during the AST could in principle originate either from the degradation of the catalysts or from some other mechanism of apparent surface loss (i.e. poisoning by the impurities). Such a fast initial loss of the ESA could suggest that the poisoning of the catalyst may occur concurrently with the degradation. Although this seems unlikely due to the clean conditions during activation, in order to rule out this possibility, 500 fast scans were performed up to 

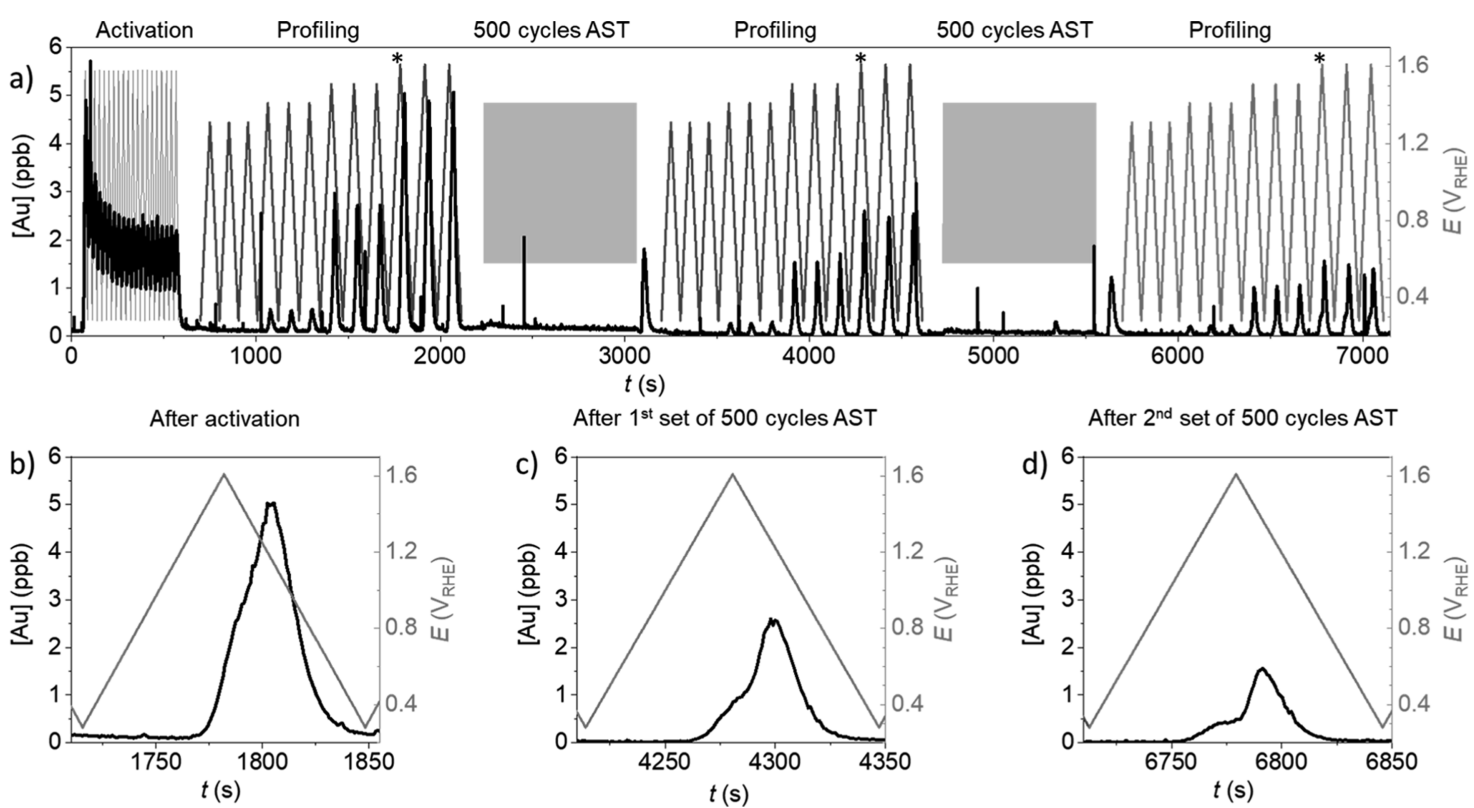

Figure 4. Au dissolution as a function of the applied electrochemical protocol in the EFC-ICP-MS system in $0.05 \mathrm{M} \mathrm{H}_{2} \mathrm{SO}_{4}$. (a) applied potential protocol: activation $\left(20\right.$ cycles, $\left.100 \mathrm{mV} / \mathrm{s}, 0.28-1.58 \mathrm{~V}_{\mathrm{RHE}}\right)$, a set of 3 cycles $(20 \mathrm{mV} / \mathrm{s})$ from $0.28 \mathrm{~V}_{\mathrm{RHE}}$ to a given UPL $(1.31,1.41,1.51$, and 1.61 $\left.\mathrm{V}_{\mathrm{RHE}}\right)$. Then, the material was subjected to 500 cycles of AST $\left(1 \mathrm{~V} / \mathrm{s}, 0.58-1.41 \mathrm{~V}_{\mathrm{RHE}}\right)$ before the profiling was repeated to analyze the degradation-induced changes. The sequence of degradation and profiling was repeated once more. After each AST protocol, the electrolyte flow was switched from one syringe to another, causing a signal peak unrelated to sample dissolution. A close-up of all the protocols is available in Figure $\mathrm{S} 5 \mathrm{a}-\mathrm{f}$. Three profiling cycles (marked with *) with an UPL of $1.61 \mathrm{~V}_{\mathrm{RHE}}$ are selected for comparison of the dissolution profile (b) before AST, (c) after the first 500 AST cycles, and (d) after the second 500 cycles.

different UPLs in the neat $0.05 \mathrm{M} \mathrm{H}_{2} \mathrm{SO}_{4}$ electrolyte (Figure S4). After 500 fast scans up to UPLs of 1.21 and $1.31 \mathrm{~V}_{\mathrm{RHE}}$, the loss of the gold ESA was below 2 and 4\%, respectively. This is expected for the applied UPLs at which gold oxidation does not occur $\left(1.21 \mathrm{~V}_{\mathrm{RHE}}\right)$ or is at its very beginning $\left(1.31 \mathrm{~V}_{\mathrm{RHE}}\right)$. When the UPL is increased to $1.51 \mathrm{~V}_{\mathrm{RHE}}$, the loss of the $\mathrm{Au}$ surface area correspondingly increases to $\sim 38 \%$ over the first 500 fast scans. Since the loss of Au ESA clearly depends on the applied UPL, it can be concluded that the degradation of the catalyst is the major reason for it and not a random poisoning mechanism due to the presence of impurities.

As mentioned before, gold dissolves via a transient dissolution mechanism during potential cycling with a UPL up to $1.60 \mathrm{~V}_{\mathrm{RHE}}{ }^{22-26,29}$ In order to confirm that transient dissolution is also dominant during the AST applied in this study, a fresh catalyst film has been subjected to a potentiostatic degradation protocol by setting the potential at $1.41 \mathrm{~V}_{\mathrm{RHE}}$ for $15 \mathrm{~min}$, which is comparable to the time needed for 500 fast scans in the AST (Figure S4). This potentiostatic treatment leads to the loss of gold ESA of 5\%, which is notably less than the loss observed after the first 500 fast scans of the AST (>20\%). This confirms that the transient dissolution is indeed dominant during the AST, while anodic dissolution occurs as well but to a much lower extent.

To summarize, our experiments showed that gold NPs suffer degradation during the hereby applied AST as significant loss of ESA has been observed. The results also show that even very low amounts of chlorides, such as $10^{-4} \mathrm{M}$, which could be correlated with the low levels of chloride impurities, significantly promote degradation of $\mathrm{Au}$ NPs. If the concentration of chlorides is increased to $10^{-2} \mathrm{M}$, the electrochemical response of gold is quickly lost, which is interesting from the recycling point of view when excessive amounts of chlorides are used. ${ }^{42}$ Regarding the degradation mechanism, it has been shown that for $\mathrm{Pt} / \mathrm{C}$ fuel cell catalysts, different mechanisms can take place, either individually or simultaneously. These include particle detachment, dissolution, re-deposition, agglomeration, and carbon support corrosion. $^{20,35}$ In order to distinguish between the possible degradation mechanisms for the case of carbon-supported gold NPs, potential-resolved dissolution profiles were recorded by EFC-ICP-MS, gas evolution was followed by EC-MS, and IL-SEM and IL-TEM imaging of the $\mathrm{Au} / \mathrm{C}$ samples were performed.

3.3. Online Measurements with an EFC Coupled to ICP-MS and EC-MS. To complement the RDE data on the loss of the active surface area, the amount of electrochemically dissolved $\mathrm{Au}$ in terms of mass was tracked with an EFC-ICPMS system. This is a powerful combination of complementary techniques that allows an in-depth study of the potential- and time-resolved dissolution of metal electrocatalysts. The approach is based on analysis of an electrolyte that flows continuously through an EFC using an ICP-MS detector. The latter provides data on the concentration of the dissolved $\operatorname{metal}(\mathrm{s})$ as a function of the applied electrochemical experiment. The results give a direct insight into the dissolution mechanism and enable quantifying the amount of dissolved metal.

The applied electrochemical protocol used in this study is shown in Figure 4. Similarly like in RDE tests, a set of 20 activation cycles was first performed $(100 \mathrm{mV} / \mathrm{s}, 0.28-1.58$ $\mathrm{V}_{\mathrm{RHE}}$ ) in order to achieve a stable and reproducible dissolution response (see close-up in Figure S5a) before continuing with a protocol of slow $(20 \mathrm{mV} / \mathrm{s})$ potential cycles to reveal the dissolution mechanism (close-up in Figure S5d-f). Three cycles were repeated within the selected potential range before the UPL was increased by $100 \mathrm{mV}$. Four ranges from 0.28 $\mathrm{V}_{\mathrm{RHE}}$ to an increasing UPL $\left(1.31 ; 1.41 ; 1.51\right.$; and $\left.1.61 \mathrm{~V}_{\mathrm{RHE}}\right)$ 


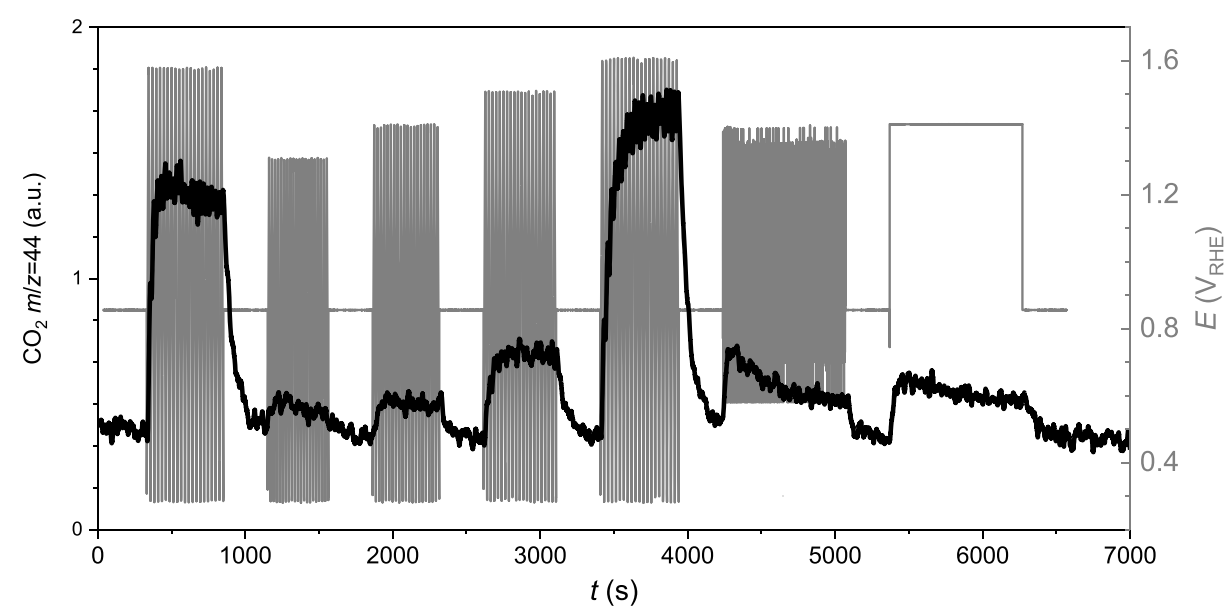

Figure 5. EC-MS dissolution profiles showing the signal for $\mathrm{m} / z=44$, attributed to $\mathrm{CO}_{2}$, as a function of electrode potential. The electrochemical protocol applied to $\mathrm{Au} / \mathrm{C}$ in $0.05 \mathrm{M} \mathrm{H}_{2} \mathrm{SO}_{4}$ consisted of 20 activation cycles $\left(100 \mathrm{mV} / \mathrm{s}, 0.28-1.58 \mathrm{~V}_{\mathrm{RHE}}\right)$, followed by sets of $20 \mathrm{cycles}(100 \mathrm{mV} /$ s) from $0.28 \mathrm{~V}_{\mathrm{RHE}}$ to an increasing UPL, namely, 1.31, 1.41, 1.51, and $1.61 \mathrm{~V}_{\mathrm{RHE}}$. This was followed by the AST (500 cycles, $1 \mathrm{~V} / \mathrm{s}, 0.58-1.41$ $\mathrm{V}_{\mathrm{RHE}}$ ) and a $15 \mathrm{~min}$ potential hold at $1.41 \mathrm{~V}_{\mathrm{RHE}}$. Sets of cycles were separated by $5 \mathrm{~min}$ of open circuit potential to allow for background stabilization.

were thus examined. As expected, no detectable Au dissolution occurs when cycling the potential to a UPL of $1.31 \mathrm{~V}_{\mathrm{RHE}}$. Increasing the upper potential to $1.41 \mathrm{~V}_{\mathrm{RHE}}$, however, causes a transient dissolution event that appears as a peak during the cathodic scan direction. This confirms that in the potential range chosen for the AST, only the transient mode of dissolution occurs. Even when cycling the electrode up to 1.51 $\mathrm{V}_{\mathrm{RHE}}$, this transient cathodic dissolution mechanism is still the only clearly distinguishable degradation process, but at 1.61 $\mathrm{V}_{\mathrm{RHE}}$, a distinct shoulder appears prior to the transient dissolution peak, which can be attributed to anodic dissolution (Figure $4 \mathrm{~b}$ ). This is consistent with the reports that the transient dissolution mechanism is dominant up to a UPL of around $1.60 \mathrm{~V}_{\mathrm{RHE}}$, while at higher anodic UPLs, the direct anodic dissolution prevails. ${ }^{22-26}$

It is well known from the literature that oxidation and dissolution behaviors of NPs in electrochemical environments can differ from bulk behavior and are also size-dependent. $^{29,30,48}$ When the distribution changes, this inevitably influences the dissolution behavior and should be apparent from the dissolution profiles. Focusing on the potential range where both dissolution mechanisms occur (0.28-1.61 $\left.\mathrm{V}_{\mathrm{RHE}}\right)$ can offer insights into how the material structure evolves as a consequence of the applied ASTs. One of the three cycles with the highest UPL is shown after 500 and 1000 AST cycles (Figure $4 c, d$, respectively). The most notable change, that is, the lowering of the concentrations of dissolved $\mathrm{Au}$, is consistent with the severe loss of the surface area observed in the $\mathrm{RDE}$ experiments. More insightful, however, is the change of the shape of the peaks. After each set of degradation cycles, the anodic shoulder becomes more pronounced. Deconvolution and integration of both peaks indeed confirm that the ratio of anodically versus cathodically dissolved $\mathrm{Au}$ increases from 8:92 to 9:91 and 12:88 after activation and the first and the second AST cycle, respectively (Figure S6). In other words, the contribution of the transient dissolution relative to the anodic dissolution is lowering with degradation. Apparently, the AST degradation protocol, which occurs exclusively via the transient cathodic dissolution, induces structural changes in the material which not only drastically decrease the Au ESA but also reflect in the change of the dissolution profiles at higher potentials. The dissolution mechanism of $\mathrm{Au}$ NPs is known to be affected by their size, ${ }^{29,30}$ which suggests that the population of particles (namely, their size distribution) changes with degradation. Comparing the PSDs before and after degradation (Figure $S 7 a, b)$ reveals that the population of the as-purchased sample is much richer in particles smaller than $10 \mathrm{~nm}$ than the sample after 10,000 AST degradation cycles. This is consistent with the reported particle size effect, ${ }^{29,30,48}$ which indicates that smaller particles are generally more prone to dissolution. PSD is therefore very closely linked with the degradation effects; namely, the population of the particle sizes determines the observed degradation effects and vice versa-degradation dynamically changes the size distribution. However, we cannot exclude the possibility of dissolution of a thin surface layer of gold from larger Au NPs, which can also subtly contribute to the detected amount of dissolved gold. This is addressed in more detail in the microscopy section below (3.4 IL-SEM and IL-TEM Imaging).

The EFC-ICP-MS setup enables quantifying the amount of dissolved $\mathrm{Au}$ through peak integration. Given that the loss of ESA in the RDE tests in neat $\mathrm{H}_{2} \mathrm{SO}_{4}$ is already significant in the first 500 cycles $(>20 \%)$, it may seem unexpected that in the EFC-ICP-MS setup, only about $0.02 \%$ of the total mass of $\mathrm{Au}$ is lost in a set of 500 AST cycles. This amount was determined by integrating the notably low dissolution signal (with subtracted background) during the 500 AST cycles (Figure $S 5 b, c)$. By extrapolating this number to 10,000 cycles, it can be estimated that only about $0.4 \%$ of Au mass is lost at the same time when the total surface drops by $65 \%$. Although this is not an intuitively expected ratio, it can be elegantly explained by taking into account the polydisperse nature of the Au NPs in the material. From the size distribution analysis of the fresh sample (Figures 1c and S7a), it can be estimated that all the particles with $d \leq 5 \mathrm{~nm}$ together contribute about $66 \%$ to the total Au surface area and only $3 \%$ to the total mass. It should be stressed, however, that only particles smaller than $30 \mathrm{~nm}$ were taken into account for the PSD and that much larger particles were also observed in the material. They were intentionally omitted from the PSD because their relative rarity and nonhomogeneous distribution would introduce great 


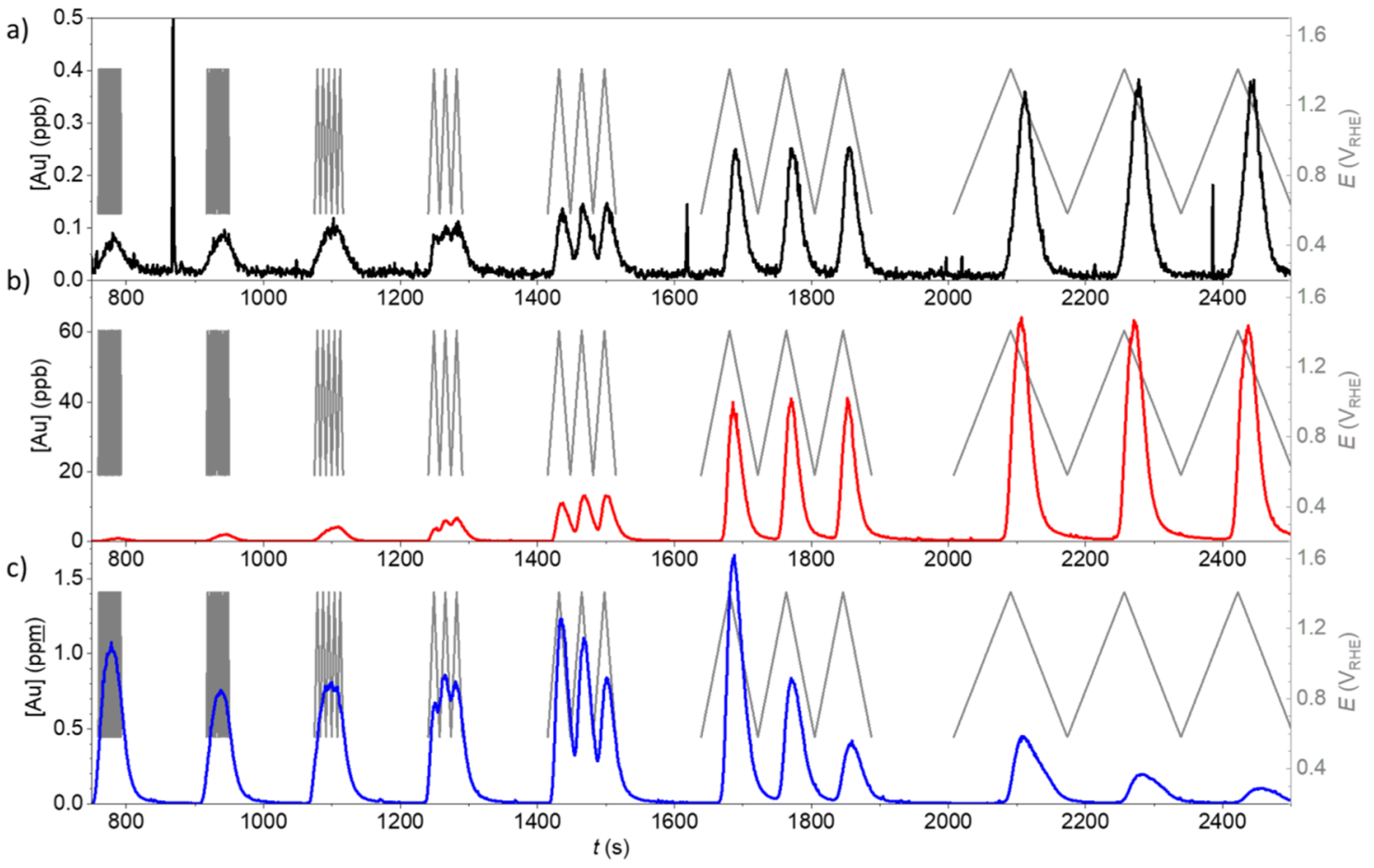

Figure 6. Au dissolution profiles of the $\mathrm{Au} / \mathrm{C}$ in (a) $0.05 \mathrm{M} \mathrm{H}_{2} \mathrm{SO}_{4}$, (b) $0.05 \mathrm{M} \mathrm{H}_{2} \mathrm{SO}_{4}+10^{-4} \mathrm{Cl}^{-}$, and (c) $0.05 \mathrm{M} \mathrm{H}_{2} \mathrm{SO}_{4}+10^{-2} \mathrm{Cl}^{-}$. The applied potential protocol was the same in all three cases. First, 20 activation cycles $\left(0.28-1.58 \mathrm{~V}_{\mathrm{RHE}}, 100 \mathrm{mV} / \mathrm{s}\right)$ were applied in chloride-free $0.05 \mathrm{M}$ $\mathrm{H}_{2} \mathrm{SO}_{4}$ (not shown). For experiments in the chloride-containing electrolyte, the electrolyte was then switched during the 5 min wait period following the activation. The following cycles (shown in the graph) were recorded in the AST potential range, namely, $0.58-1.41 \mathrm{~V}_{\mathrm{RHE}}$ with a varying scan rate: $1000 \mathrm{mV} / \mathrm{s}$ (20 cycles), $500 \mathrm{mV} / \mathrm{s}(10$ cycles $), 200 \mathrm{mV} / \mathrm{s}(5 \mathrm{cycles}), 100 \mathrm{mV} / \mathrm{s}(3 \mathrm{cycles}), 50 \mathrm{mV} / \mathrm{s}(3 \mathrm{cycles}), 20 \mathrm{mV} / \mathrm{s}(3$ cycles), and $10 \mathrm{mV} / \mathrm{s}$ (3 cycles). Sets of cycles were separated by 2 min of open circuit potential to allow background stabilization.

statistical unreliability. It is however straightforward to imagine that taking into account also the randomly observed larger particles (see Figure S1) would make the total contribution of particles smaller than $5 \mathrm{~nm}$ to the overall mass even smaller (but in unreliable fashion) and in agreement with the low observed dissolution. We are thus making a very conservative judgment. These EFC-ICP-MS results together with the changes of the size distribution (Figure S7) suggest that the AST predominantly dissolves small Au NPs and thus dramatically lowers ESA, while the actual dissolution of $\mathrm{Au}$ remains low due to the presence of large particles (up to $30 \mathrm{~nm}$ and larger) that are not significantly affected by the AST but carrying the vast majority of the mass. The other possibility for low Au dissolution detected by EFC-ICP-MS could be that $\mathrm{Au}$ is being dissolved and redeposited back according to the Ostwald ripening. This mechanism would also lead to the observed loss of Au ESA, due to particle growth. In order to distinguish between different possible degradation mechanisms, namely, to show that there is no Au re-deposition or Ostwald ripening, identical location electron microscopy was performed (see below Section 3.4).

Another possible degradation mechanism is the oxidation of the carbon support, which can cause particle detachment. ${ }^{36}$ To check whether carbon corrosion occurs in the potential range of AST, the amount of released $\mathrm{CO}_{2}$ was monitored with an electrochemistry-mass spectrometry (EC-MS) system that enables detection of the released volatile species as a result of the applied potential protocol. The $\mathrm{CO}_{2}$ signal was detected in all of the investigated potential intervals, including those with a UPL as low as $1.31 \mathrm{~V}_{\mathrm{RHE}}$ (Figure 5). Carbon degradation was thus confirmed in the AST regime; however, it did not differ much from the amount of $\mathrm{CO}_{2}$ released during 15 min of potential hold at the UPL of degradation (1.41 $\mathrm{V}_{\mathrm{RHE}}$ ) where ESA is practically not affected. This suggests that carbon oxidation does not contribute to the significant difference that was observed in ESA loss between potentiodynamic and potentiostatic protocols; hence, it may be concluded that it does not notably contribute to the overall catalyst degradation. Interestingly, the addition of chlorides does not affect the corrosion of carbon (Figure S8).

While fast potentiodynamic degradation in pure $\mathrm{H}_{2} \mathrm{SO}_{4}$ proved detrimental for the Au surface area, which is of course of tremendous importance for electrocatalytic applications, its selective targeting of small NPs in the polydisperse population results only in a minute $\mathrm{Au}$ mass loss. For exploring the options of electrochemical dissolution of $\mathrm{Au}$ with the purpose of recycling, however, it is the loss of $\mathrm{Au}$ mass that is the crucial parameter of interest. For this reason, EFC-ICP-MS experiments were also carried out in $\mathrm{H}_{2} \mathrm{SO}_{4}$ containing the addition of $10^{-4}$ and $10^{-2} \mathrm{M} \mathrm{Cl}^{-}$(Figure 6). Only one potential regime was tested for this purpose, namely, the AST potential window $\left(0.58\right.$ to $\left.1.41 \mathrm{~V}_{\mathrm{RHE}}\right)$, but the scan rate was varied from $1 \mathrm{~V} / \mathrm{s}$ to $10 \mathrm{mV} / \mathrm{s}$. Adding even small amounts of chlorides $\left(10^{-4} \mathrm{M}\right)$ increased $\mathrm{Au}$ dissolution by several folds (pay attention to the dissolved $\mathrm{Au}$ concentration scale). At the same time, however, the shape of the peaks remained the same, suggesting that the dissolution with $\mathrm{Cl}^{-}$assistance occurs transiently during cathodic reduction.

Increasing the $\mathrm{Cl}^{-}$concentration to $10^{-2} \mathrm{M}$ is expectedly even more efficient for $\mathrm{Au}$ leaching. Not only does the dissolution increase several thousand times as compared to the chloride-free electrolyte, the experiment actually dissolves a 


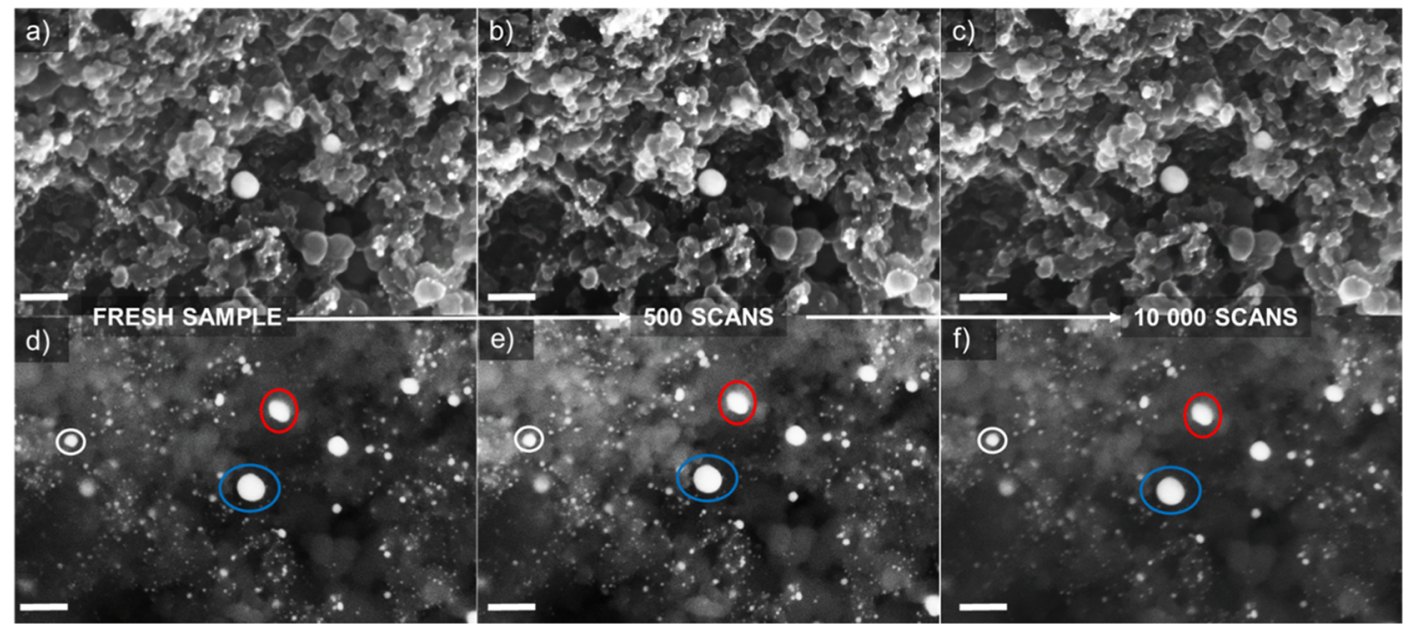

Figure 7. IL-SEM imaging of the Au/C sample during AST in neat $0.05 \mathrm{M} \mathrm{H}_{2} \mathrm{SO}_{4}$ : (a,d) fresh sample; (b,e) after 500 scans; (c,f) after 10,000 scans. The potential window used for AST was between 0.58 and $1.41 \mathrm{~V}_{\mathrm{RHE}}$, while the scan rate was $1 \mathrm{~V} / \mathrm{s}$. Scale bars correspond to $100 \mathrm{~nm}$. The upper row of images was obtained using an in-lens detector, while the lower row was obtained using a SE2 detector.

majority of $\mathrm{Au}$ present in the tested sample, which causes a significant signal drop toward the second half of the experiment. Integration of the dissolution peaks reveals that the total percentage of dissolved Au mass increases from 0.02 wt $\%$ in pure $\mathrm{H}_{2} \mathrm{SO}_{4}$ to about 4 wt $\%$ when $10^{-4} \mathrm{M}$ of chloride is added and to over $100 \mathrm{wt} \%$ in the solution containing $10^{-2}$ $\mathrm{Cl}^{-}$. The Au loading stated by the producer was not checked; therefore, the numbers should not be interpreted exactlynevertheless they reveal the order of magnitude of dissolution increase caused by the presence of chlorides. Although more thorough investigations are necessary, this simple experiment clearly confirms that the principle of electrochemical dissolution of noble metals under mild conditions developed for $\mathrm{Pt}^{42}$ can be extended to Au.

3.4. IL-SEM and IL-TEM Imaging. In order to observe the degradation of the $\mathrm{Au} / \mathrm{C}$ catalyst on a local level and to identify the dominating degradation mechanism, IL-SEM imaging of the samples before, in between, and after AST has been performed. Figure 7 presents successive IL-SEM imaging of the untreated $\mathrm{Au} / \mathrm{C}$ sample (Figure 7a,d), after 500 (Figure $7 \mathrm{~b}, \mathrm{e}$ ) and 10,000 (Figure 7c,f) fast scans during AST in the neat $0.05 \mathrm{M} \mathrm{H}_{2} \mathrm{SO}_{4}$.

One can see that any change in these consecutive IL-SEM images is quite subtle as there are no clearly observable differences, such as missing Au NPs due to the dissolution or particles that have grown due to the redeposition or coalescence. In the case of the $\mathrm{Pt} / \mathrm{C}$ catalyst, the obvious growth of $\mathrm{Pt}$ particles during degradation was easily observed by $\mathrm{IL}-S E M^{18,19}$ pointing out the redeposition as the main degradation mechanism. In the case of $\mathrm{Au} / \mathrm{C}$, there is no notable growth of larger NPs (few examples of unchanged particles are highlighted in Figure $7 \mathrm{~d}-\mathrm{f}$ by the circles of the same color) which means that redeposition is not a degradation mechanism responsible for the loss of ESA during the AST. Due to the resolution limitations, IL-SEM alone cannot unequivocally confirm the assumption derived from EFC-ICP-MS results that the predominant degradation mechanism responsible for the loss of gold ESA is the dissolution of a significant fraction of the smallest particles (smaller than approximately $5 \mathrm{~nm}$ ). To check for the structural changes in NPs in the size range below $5 \mathrm{~nm}$, IL-TEM imaging was performed before and after AST in the $0.05 \mathrm{M} \mathrm{H}_{2} \mathrm{SO}_{4}$ electrolyte free of chlorides (Figure 8). Figure 8a shows a representative STEM ADF image of a fresh sample and

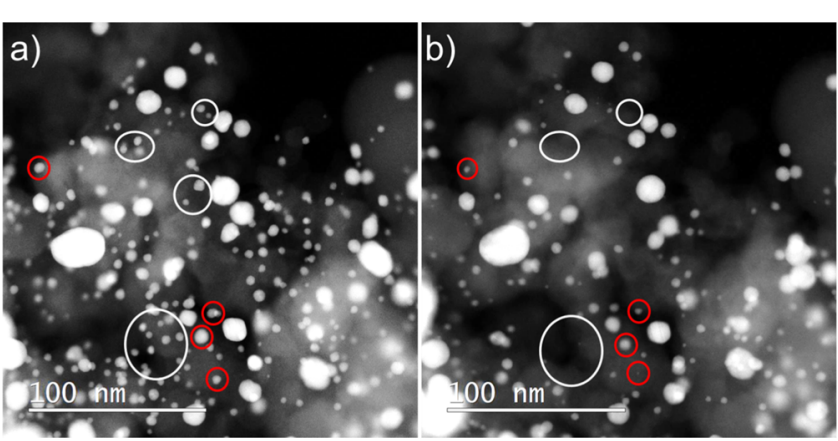

Figure 8. IL-TEM imaging of the $\mathrm{Au} / \mathrm{C}$ sample: (a) before and (b) after AST in the neat $0.05 \mathrm{M} \mathrm{H}_{2} \mathrm{SO}_{4}$. The potential window used for AST was between 0.58 and $1.41 \mathrm{~V}_{\mathrm{RHE}}$, while the scan rate was $1 \mathrm{~V} / \mathrm{s}$.

confirms the discussion related to the TEM image from Figure $\mathrm{lb}$, according to which the commercial $\mathrm{Au} / \mathrm{C}$ catalyst contains mainly spherical Au NPs, polydisperse in size, and well distributed over the carbon support. Figure $8 \mathrm{~b}$ shows the corresponding STEM imaging of the same location on the sample after AST in the $0.05 \mathrm{M} \mathrm{H}_{2} \mathrm{SO}_{4}$ electrolyte. Clearly, using TEM makes it possible to discern the changes that occur in the smallest particles in the Au/C sample during the AST in the $0.05 \mathrm{M} \mathrm{H}_{2} \mathrm{SO}_{4}$ electrolyte. One can see that a notable share of the particles, mostly smaller than $5 \mathrm{~nm}$, is missing after the AST, while larger particles are less affected. At such high magnifications, the individual particles that have undergone complete dissolution can be resolved, as few examples are marked by white circles in Figure $8 \mathrm{a}, \mathrm{b}$. Red circles in these figures are highlighting the particles that have decreased in size due to the dissolution. In agreement with IL-SEM imaging from Figure 7, no other degradation mechanism except dissolution can be observed. Therefore, IL-TEM provides an indisputable proof that degradation of the $\mathrm{Au} / \mathrm{C}$ sample during the AST occurs through the dissolution of particles below 5 $\mathrm{nm}$. Degradation of gold NPs is clearly size-dependent as the larger particles are less prone to dissolution than the smaller ones in the neat $0.05 \mathrm{M} \mathrm{H}_{2} \mathrm{SO}_{4}$ electrolyte. This is in 


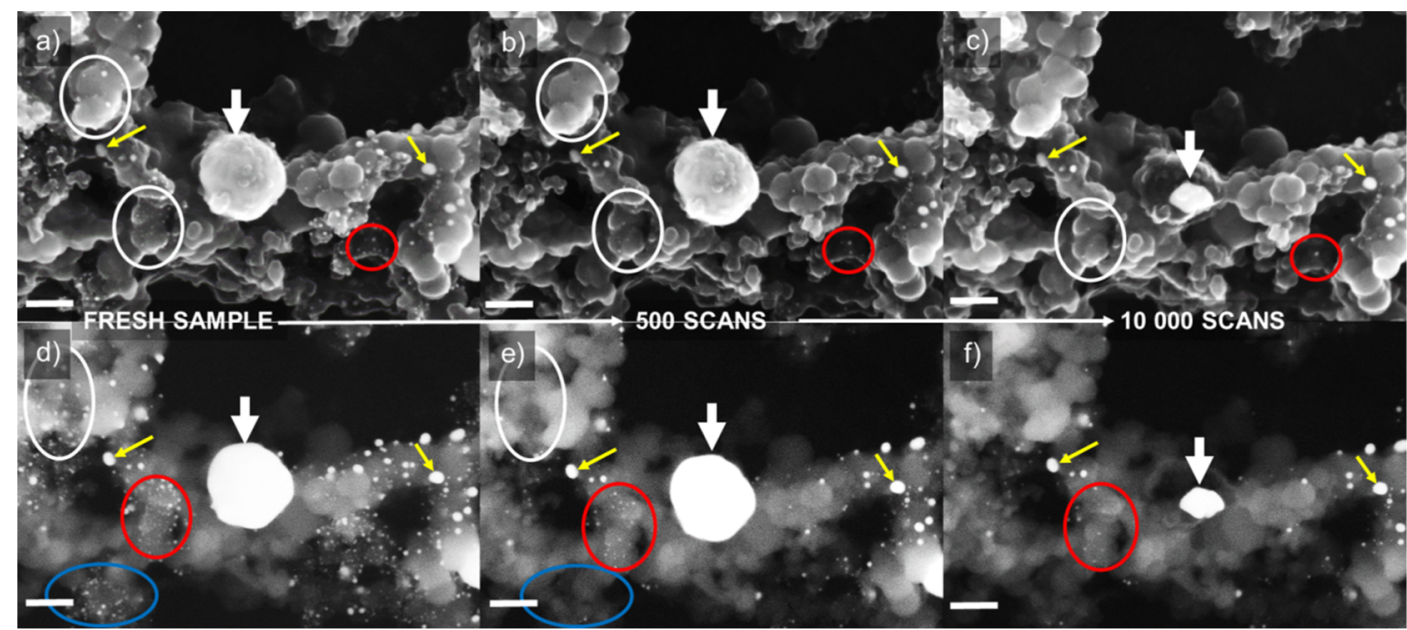

Figure 9. IL-SEM imaging of the Au/C sample during AST in $0.05 \mathrm{M} \mathrm{H}_{2} \mathrm{SO}_{4}+10^{-4} \mathrm{M} \mathrm{Cl}^{-}$; (a,d) fresh sample; (b,e) after 500 scans; (c,f) after 10,000 scans. The potential window used for AST was between 0.58 and $1.41 \mathrm{~V}_{\mathrm{RHE}}$, while the scan rate was $1 \mathrm{~V} / \mathrm{s}$. Scale bars correspond to $100 \mathrm{~nm}$. Circles and arrows of the same colors correspond to the changes at the identical locations in consecutive images. The upper row of images was obtained using an in-lens detector, while the lower row was obtained using the SE2 detector.

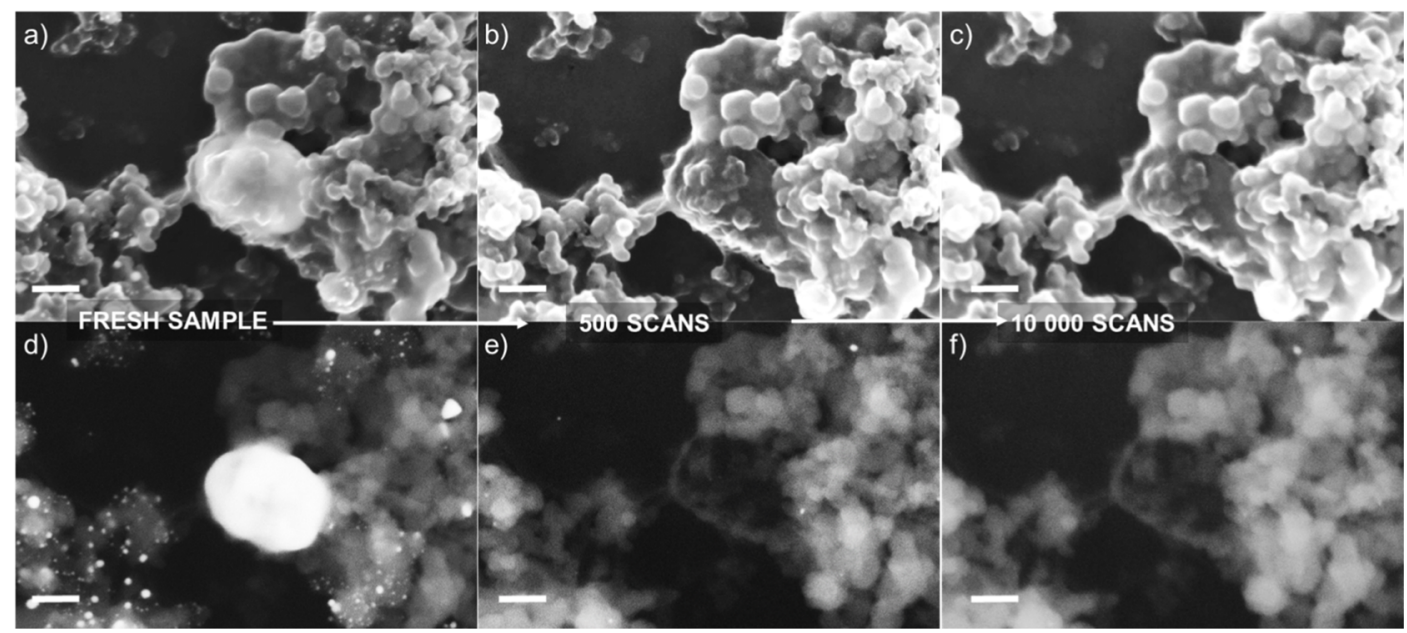

Figure 10. IL-SEM imaging of the Au/C sample during AST in $0.05 \mathrm{M} \mathrm{H}_{2} \mathrm{SO}_{4}+10^{-2} \mathrm{M} \mathrm{Cl}^{-}$: (a,d) fresh sample; (b,e) after 500 scans; (c,f) after 10,000 scans. Scale bars correspond to $100 \mathrm{~nm}$. Upper row of images was obtained using the in-lens detector, while the lower row was obtained using the SE2 detector.

agreement with the discussion from Section 3.3, where rather low amounts of gold detected by EFC-ICP-MS during AST were connected with the dissolution of particles smaller than 5 $\mathrm{nm}$, whose contribution to the overall mass is rather low, while their contribution to the overall surface area of the sample is rather high. As mentioned earlier, discrete dissolution of the thin surface layer of gold from larger particles can occur to a certain extent during AST, which would also result with a minor amount of dissolved gold.

As expected and in accordance with the results of the AST and EFC-IPC-MS, much more pronounced changes in the ILSEM imaging can be observed in the presence of chlorides. Consecutive changes showing the degradation of the $\mathrm{Au} / \mathrm{C}$ sample in $0.05 \mathrm{M} \mathrm{H}_{2} \mathrm{SO}_{4}+10^{-4} \mathrm{M} \mathrm{Cl}^{-}$are highlighted with dotted circles of the same colors in Figure 9. Figure 9a,d, corresponding to the fresh $\mathrm{Au} / \mathrm{C}$ sample, is focused around particularly a large Au NP, which is marked by a white arrow in Figure 9.

After the first 500 scans (Figure 9b,e), a significant portion of smaller particles is not present anymore in the sample with some of the medium size particles being absent as well. Larger particles seem to be more stable than the smaller ones, for example, the central one marked by white arrow has not suffered any notable change after the initial 500 scans, which complies with the particle size effect. ${ }^{29}$ One should note that due to the resolution, smaller particles that we refer to in these SEM images are much larger than the small particles that we refer to in IL-TEM imaging (below $5 \mathrm{~nm}$ ). This means that in the case of AST in the presence of $10^{-4} \mathrm{M} \mathrm{Cl}^{-}$, the small particles that are missing after the first 500 fast scans are larger than those identified missing by IL-TEM in the case of the AST in the absence of chlorides. At the end of the AST (Figure $9 c, f)$, the same trend for the smaller particles continues, while also the central large particle has dramatically shrunk due to dissolution. This means that in the presence of chloride, the particle size has a lower impact on their stability (i.e. the particle size effect is diminishing). Interestingly, some of the particles remained intact in the sample throughout the whole AST (few examples are marked by yellow arrows in Figure 9). 
These particles could be well-protected by surrounding the carbon material and thus electrochemically inactive. ${ }^{49}$

According to the results of the AST from Figure 3, when the concentration of chlorides is increased to $10^{-2} \mathrm{M}$, degradation becomes fast and severe. Consecutive IL-SEM imaging of the sample during the AST performed in the $0.05 \mathrm{M} \mathrm{H}_{2} \mathrm{SO}_{4}+10^{-2}$ $\mathrm{M} \mathrm{Cl}^{-}$electrolyte is given in Figure 10 and confirms the trend observed in the AST. It can be seen that almost all particles from the fresh sample (Figure 10a,d), regardless of their size, have disappeared from the sample after the first 500 scans (Figure 10b,f). Even the particularly large particle in the center of the sample is completely dissolved after the first 500 fast scans. At lower magnification in this location, as well as on the other random places across the sample, we have observed that some groups of the particles remain present throughout the AST even under such harsh conditions. This can again be explained by encapsulation of the Au particles by the carbon material, ${ }^{49}$ which makes them electrochemically inaccessible and therefore intact. Another possibility for this is that some particles are not electrically connected with the electrode. Regarding the (in)stability of the $\mathrm{Au} / \mathrm{C}$ sample in the presence of chlorides, we may conclude that the results obtained in this study show that the (electro)chemical approach developed by Hodnik for platinum recycling ${ }^{42}$ can be adopted and optimized for the recycling of gold in the presence of the higher amount of chlorides.

\section{CONCLUSIONS}

In this work, we studied the stability and degradation mechanism of a commercial carbon-supported gold NPs during ASTs in $0.05 \mathrm{M} \mathrm{H}_{2} \mathrm{SO}_{4}$ in the absence and presence of chloride ions. Over the course of AST in the sulfuric acid solution, gradual decay of the Au ESA was observed, which was expectedly more pronounced in the presence of chlorides. According to EFC-ICP-MS measurements, under the conditions applied in the AST, the dissolution of gold NPs occurs transiently and is strongly enhanced by the presence of chlorides. EFC-ICP-MS experiments also showed that a low amount of gold was dissolved during the AST, which can be explained by the predominant dissolution of small Au NPs (below $5 \mathrm{~nm}$ ). The latter contributes modestly to the overall mass but notably to the overall electrochemical surface area of the polydisperse $\mathrm{Au} / \mathrm{C}$ sample. EC-MS measurements showed that carbon corrosion also occurs during AST, but to a smaller extent so that it does not significantly contribute to the overall degradation of the sample. Due to the resolution limitations, it was not possible to observe changes that occur in the smallest $\mathrm{Au}$ NPs in the polydisperse sample during the AST in the neat $0.05 \mathrm{M} \mathrm{H}_{2} \mathrm{SO}_{4}$ by IL-SEM; however, it was possible to exclude redeposition of previously dissolved gold NPs (i.e. Ostwald ripening) as a degradation mechanism. Corresponding ILTEM imaging before and after the AST in pure $0.05 \mathrm{M} \mathrm{H}_{2} \mathrm{SO}_{4}$ revealed that indeed dissolution of small $\mathrm{Au}$ particles, mainly below $5 \mathrm{~nm}$, takes place, confirming thus the hypotheses derived from EFC-ICP-MS. Due to the polydispersity of the sample, it was possible to observe the size-dependent nature of dissolution of gold NPs, which expectedly showed that the smaller particles were less stable. In the case of chloridecontaining electrolytes, the dissolution was substantially increased and thus recognized as the main degradation mechanism by IL-SEM. Therefore, results obtained in this work show that the instability of gold NPs, especially the ones with a diameter below $5 \mathrm{~nm}$, must be taken into account when considering the application of gold in electrochemical energy storage and conversion devices (for example, as (co)catalyst in fuel cells where similar potentials can be reached during start/ stop conditions). On the other hand, this work also shows that the approach developed for Pt recycling ${ }^{42}$ can be extended and optimized for the recycling of gold in the presence of chloride ions due to the transient nature of gold dissolution.

\section{ASSOCIATED CONTENT}

\section{Supporting Information}

The Supporting Information is available free of charge at https://pubs.acs.org/doi/10.1021/acs.jpcc.0c10033.

Additional TEM images of the Au/C catalyst; development of $\mathrm{Au}$ ESA during electrochemical activation; tracking of the gold ESA decay during the AST; comparison of Au ESA loss during different potentiodynamic and potentiostatic treatments; effect of degradation during the AST on the dissolution profile of $\mathrm{Au} / \mathrm{C}$ determined by EFC-ICP-MS; changes in the contributions of anodic and cathodic Au dissolution during the AST; PSD with distribution of mass and surface area; and carbon corrosion monitoring during the AST by EC-MS (PDF)

\section{AUTHOR INFORMATION}

\section{Corresponding Authors}

Milutin Smiljanic - Department of Materials Chemistry, National Institute of Chemistry, 1000 Ljubljana, Slovenia; Laboratory for Atomic Physics, Institute for Nuclear Sciences Vinča, University of Belgrade, 11001 Belgrade, Serbia; ○ orcid.org/0000-0002-4911-5349;

Email: milutin.smiljanic@ki.si

Nejc Hodnik - Department of Materials Chemistry, National Institute of Chemistry, 1000 Ljubljana, Slovenia; University of Nova Gorica, 5000 Nova Gorica, Slovenia; 이이.org/ 0000-0002-7113-9769; Email: nejc.hodnik@ki.si

\section{Authors}

Urša Petek - Department of Materials Chemistry, National Institute of Chemistry, 1000 Ljubljana, Slovenia

Marjan Bele - Department of Materials Chemistry, National Institute of Chemistry, 1000 Ljubljana, Slovenia

Francisco Ruiz-Zepeda - Department of Materials Chemistry, National Institute of Chemistry, 1000 Ljubljana, Slovenia; Department of Physics and Chemistry of Materials, Institute of Metals and Technology, 1000 Ljubljana, Slovenia

Martin Sala - Department of Analytical Chemistry, National Institute of Chemistry, 1000 Ljubljana, Slovenia; (1) orcid.org/0000-0001-7845-860X

Primož Jovanovič - Department of Materials Chemistry, National Institute of Chemistry, 1000 Ljubljana, Slovenia; (1) orcid.org/0000-0003-2477-3895

Miran Gaberšcek - Department of Materials Chemistry, National Institute of Chemistry, 1000 Ljubljana, Slovenia; Faculty of Chemistry and Chemical Technology, University of

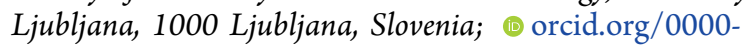
0002-8104-1693

Complete contact information is available at:

https://pubs.acs.org/10.1021/acs.jpcc.0c10033

\section{Notes}

The authors declare no competing financial interest. 


\section{ACKNOWLEDGMENTS}

This work was supported by the Ministry of Education, Science, and Sport of the Republic of Slovenia through Raziskovalci-2.1-KI-952007 and ERA-MIN2 RedOxRec projects and by the Slovenian Research Agency through the research programs P1-0034 and P2-0393 and project N2-0106. We also acknowledge funding from the NATO Science for Peace and Security Programme under grant G5729 and the European Research Council (ERC) under the European Union's Horizon 2020 research (grant agreement ID: 852208).

\section{REFERENCES}

(1) Marković, N. M.; Schmidt, T. J.; Stamenković, V.; Ross, P. N. Oxygen Reduction Reaction on Pt and Pt Bimetallic Surfaces: A Selective Review. Fuel Cells 2001, 1, 105-116.

(2) Strmcnik, D.; Lopes, P. P.; Genorio, B.; Stamenkovic, V. R.; Markovic, N. M. Design Principles for Hydrogen Evolution Reaction Catalyst Materials. Nano Energy 2016, 29, 29-36.

(3) Eftekhari, A. Electrocatalysts for Hydrogen Evolution Reaction. Int. J. Hydrogen Energy 2017, 42, 11053-11077.

(4) Shi, Q.; Zhu, C.; Du, D.; Lin, Y. Robust Noble Metal-Based Electrocatalysts for Oxygen Evolution Reaction. Chem. Soc. Rev. 2019, 48, 3181-3192.

(5) Tahir, M.; Pan, L.; Idrees, F.; Zhang, X.; Wang, L.; Zou, J.-J.; Wang, Z. L. Electrocatalytic Oxygen Evolution Reaction for Energy Conversion and Storage: A Comprehensive Review. Nano Energy 2017, 37, 136-157.

(6) Chen, S.; Chen, A. Electrochemical Reduction of Carbon Dioxide on Au Nanoparticles: An in Situ FTIR Study. J. Phys. Chem. C 2019, 123, 23898-23906.

(7) Zhao, S.; Jin, R.; Jin, R. Opportunities and Challenges in $\mathrm{CO}_{2}$ Reduction by Gold- and Silver-Based Electrocatalysts: From Bulk Metals to Nanoparticles and Atomically Precise Nanoclusters. ACS Energy Lett. 2018, 3, 452-462.

(8) Rodriguez, P.; Koper, M. T. M. Electrocatalysis on Gold. Phys. Chem. Chem. Phys. 2014, 16, 13583-13594.

(9) Edwards, J. K.; Hutchings, G. J. Palladium and Gold-Palladium Catalysts for the Direct Synthesis of Hydrogen Peroxide. Angew. Chem., Int. Ed. 2008, 47, 9192-9198.

(10) Jirkovský, J. S.; Halasa, M.; Schiffrin, D. J. Kinetics of Electrocatalytic Reduction of Oxygen and Hydrogen Peroxide on Dispersed Gold Nanoparticles. Phys. Chem. Chem. Phys. 2010, 12, 8042-8052.

(11) Jirkovský, J. S.; Panas, I.; Ahlberg, E.; Halasa, M.; Romani, S.; Schiffrin, D. J. Single Atom Hot-Spots at Au-Pd Nanoalloys for Electrocatalytic $\mathrm{H}_{2} \mathrm{O}_{2}$ Production. J. Am. Chem. Soc. 2011, 133, 19432-19441.

(12) Siahrostami, S.; Verdaguer-Casadevall, A.; Karamad, M.; Deiana, D.; Malacrida, P.; Wickman, B.; Escudero-Escribano, M.; Paoli, E. A.; Frydendal, R.; Hansen, T. W.; et al. Enabling Direct $\mathrm{H}_{2} \mathrm{O}_{2}$ Production through Rational Electrocatalyst Design. Nat. Mater. 2013, 12, 1137-1143.

(13) Topalov, A. A.; Katsounaros, I.; Auinger, M.; Cherevko, S.; Meier, J. C.; Klemm, S. O.; Mayrhofer, K. J. J. Dissolution of Platinum: Limits for the Deployment of Electrochemical Energy Conversion? Angew. Chem., Int. Ed. 2012, 51, 12613-12615.

(14) Topalov, A. A.; Cherevko, S.; Zeradjanin, A. R.; Meier, J. C.; Katsounaros, I.; Mayrhofer, K. J. J. Towards a Comprehensive Understanding of Platinum Dissolution in Acidic Media. Chem. Sci. 2014, 5, 631-638.

(15) Cherevko, S.; Keeley, G. P.; Geiger, S.; Zeradjanin, A. R.; Hodnik, N.; Kulyk, N.; Mayrhofer, K. J. J. Dissolution of Platinum in the Operational Range of Fuel Cells. ChemElectroChem 2015, 2, 1471-1478.

(16) Schlögl, K.; Mayrhofer, K. J. J.; Hanzlik, M.; Arenz, M. Identical-Location TEM Investigations of $\mathrm{Pt} / \mathrm{C}$ Electrocatalyst
Degradation at Elevated Temperatures. J. Electroanal. Chem. 2011, 662, 355-360.

(17) Perez-Alonso, F. J.; Elkjær, C. F.; Shim, S. S.; Abrams, B. L.; Stephens, I. E. L.; Chorkendorff, I. Identical Locations Transmission Electron Microscopy Study of Pt/C Electrocatalyst Degradation during Oxygen Reduction Reaction. J. Power Sources 2011, 196, 6085-6091.

(18) Hodnik, N.; Zorko, M.; Jozinović, B.; Bele, M.; Dražič, G.; Hočevar, S.; Gaberšček, M. Severe Accelerated Degradation of PEMFC Platinum Catalyst: A Thin Film IL-SEM Study. Electrochem. Commun. 2013, 30, 75-78.

(19) Hodnik, N.; Jozinović, B.; Zorko, M.; Gaberšček, M. Stability of Commercial Pt/C Low Temperature Fuel Cell Catalyst: Electrochemical IL-SEM Study. Acta Chim. Slov. 2014, 61, 280-283.

(20) Mayrhofer, K. J. J.; Meier, J. C.; Ashton, S. J.; Wiberg, G. K. H.; Kraus, F.; Hanzlik, M.; Arenz, M. Fuel Cell Catalyst Degradation on the Nanoscale. Electrochem. Commun. 2008, 10, 1144-1147.

(21) Shao-Horn, Y.; Sheng, W. C.; Chen, S.; Ferreira, P. J.; Holby, E. F.; Morgan, D. Instability of Supported Platinum Nanoparticles in Low-Temperature Fuel Cells. Top. Catal. 2007, 46, 285-305.

(22) Cherevko, S.; Topalov, A. A.; Katsounaros, I.; Mayrhofer, K. J. J. Electrochemical Dissolution of Gold in Acidic Medium. Electrochem. Commun. 2013, 28, 44-46.

(23) Cherevko, S.; Topalov, A. A.; Zeradjanin, A. R.; Katsounaros, I.; Mayrhofer, K. J. J. Gold Dissolution: Towards Understanding of Noble Metal Corrosion. RSC Adv. 2013, 3, 16516-16527.

(24) Cherevko, S.; Zeradjanin, A. R.; Topalov, A. A.; Keeley, G. P.; Mayrhofer, K. J. J. Effect of Temperature on Gold Dissolution in Acidic Media. J. Electrochem. Soc. 2014, 161, H501-H507.

(25) Kasian, O.; Kulyk, N.; Mingers, A.; Zeradjanin, A. R.; Mayrhofer, K. J. J.; Cherevko, S. Electrochemical Dissolution of Gold in Presence of Chloride and Bromide Traces Studied by OnLine Electrochemical Inductively Coupled Plasma Mass Spectrometry. Electrochim. Acta 2016, 222, 1056-1063.

(26) Cherevko, S.; Zeradjanin, A. R.; Keeley, G. P.; Mayrhofer, K. J. J. A Comparative Study on Gold and Platinum Dissolution in Acidic and Alkaline Media. J. Electrochem. Soc. 2014, 161, H822-H830.

(27) Cruickshank, A. C.; Downard, A. J. Electrochemical Stability of Citrate-Capped Gold Nanoparticles Electrostatically Assembled on Amine-Modified Glassy Carbon. Electrochim. Acta 2009, 54, 55665570.

(28) Pattadar, D. K.; Zamborini, F. P. Size Stability Study of Catalytically Active Sub-2 Nm Diameter Gold Nanoparticles Synthesized with Weak Stabilizers. J. Am. Chem. Soc. 2018, 140, 14126-14133.

(29) Jovanovič, P.; Može, M.; Gričar, E.; Šala, M.; Ruiz-Zepeda, F.; Bele, M.; Marolt, G.; Hodnik, N. Effect of Particle Size on the Corrosion Behaviour of Gold in the Presence of Chloride Impurities: An EFC-ICP-MS Potentiodynamic Study. Coatings 2019, 9, 10-21.

(30) Steven, J. T.; Golovko, V. B.; Johannessen, B.; Marshall, A. T. Electrochemical Stability of Carbon-Supported Gold Nanoparticles in Acidic Electrolyte during Cyclic Voltammetry. Electrochim. Acta 2016, 187, 593-604.

(31) Sharma, R.; Gyergyek, S.; Li, Q.; Andersen, S. M. Evolution of the Degradation Mechanisms with the Number of Stress Cycles during an Accelerated Stress Test of Carbon Supported Platinum Nanoparticles. J. Electroanal. Chem. 2019, 838, 82-88.

(32) Zana, A.; Speder, J.; Roefzaad, M.; Altmann, L.; Bäumer, M.; Arenz, M. Probing Degradation by IL-TEM: The Influence of Stress Test Conditions on the Degradation Mechanism. J. Electrochem. Soc. 2013, 160, F608-F615.

(33) Takahashi, I.; Kocha, S. S. Examination of the Activity and Durability of PEMFC Catalysts in Liquid Electrolytes. J. Power Sources 2010, 195, 6312-6322.

(34) Mayrhofer, K. J. J.; Ashton, S. J.; Meier, J. C.; Wiberg, G. K. H.; Hanzlik, M.; Arenz, M. Non-Destructive Transmission Electron Microscopy Study of Catalyst Degradation under Electrochemical Treatment. J. Power Sources 2008, 185, 734-739. 
(35) Hartl, K.; Hanzlik, M.; Arenz, M. IL-TEM Investigations on the Degradation Mechanism of $\mathrm{Pt} / \mathrm{C}$ Electrocatalysts with Different Carbon Supports. Energy Environ. Sci. 2011, 4, 234-238.

(36) Pizzutilo, E.; Geiger, S.; Grote, J.-P.; Mingers, A.; Mayrhofer, K. J. J.; Arenz, M.; Cherevko, S. On the Need of Improved Accelerated Degradation Protocols (ADPs): Examination of Platinum Dissolution and Carbon Corrosion in Half-Cell Tests. J. Electrochem. Soc. 2016, 163, F1510-F1514.

(37) Kasian, O.; Geiger, S.; Mayrhofer, K. J. J.; Cherevko, S. Electrochemical On-Line ICP-MS in Electrocatalysis Research. Chem. Rec. 2019, 19, 2130-2142.

(38) Grote, J.-P.; Zeradjanin, A. R.; Cherevko, S.; Mayrhofer, K. J. J. Coupling of a Scanning Flow Cell with Online Electrochemical Mass Spectrometry for Screening of Reaction Selectivity. Rev. Sci. Instrum. 2014, 85, 104101.

(39) Gatalo, M.; Jovanovič, P.; Polymeros, G.; Grote, J.-P.; Pavlišičc, A.; Ruiz- Zepeda, F.; Šelih, V. S.; Šala, M.; Hočevar, S.; Bele, M.; et al. Positive Effect of Surface Doping with Au on the Stability of Pt-Based Electrocatalysts. ACS Catal. 2016, 6, 1630-1634.

(40) Zhang, J.; Sasaki, K.; Sutter, E.; Adžić, R. R. Stabilization of Platinum Oxygen Reduction Catalysts Using Gold Clusters. Science 2007, 315, 220-222.

(41) Selvaganesh, S. V.; Selvarani, G.; Sridhar, P.; Pitchumani, S.; Shukla, A. K. Durable Electrocatalytic-Activity of Pt-Au/C Cathode in PEMFCs. Phys. Chem. Chem. Phys. 2011, 13, 12623-12634.

(42) Hodnik, N.; Baldizzone, C.; Polymeros, G.; Geiger, S.; Grote, J. P.; Cherevko, S.; Mingers, A.; Zeradjanin, A.; Mayrhofer, K. J. J. Platinum Recycling Going Green via Induced Surface Potential Alteration Enabling Fast and Efficient Dissolution. Nat. Commun. 2016, 7, 13164.

(43) Hodnik, N.; Jovanovič, P.; Pavlišǐ̌, A.; Jozinović, B.; Zorko, M.; Bele, M.; Šlih, V. S.; Šala, M.; Hočevar, S.; Gabeř̌ček, M. New Insights into Corrosion of Ruthenium and Ruthenium Oxide Nanoparticles in Acidic Media. J. Phys. Chem. C 2015, 119, 1014010147.

(44) Jovanovič, P.; Pavlišič, A.; Šelih, V. S.; Šala, M.; Hodnik, N.; Bele, M.; Hočevar, S.; Gaberšček, M. New Insight into Platinum Dissolution from Nanoparticulate Platinum-Based Electrocatalysts Using Highly Sensitive in Situ Concentration Measurements. ChemCatChem 2014, 6, 449-453.

(45) Trimarco, D. B.; Pedersen, T.; Hansen, O.; Chorkendorff, I.; Vesborg, P. C. K. Fast and Sensitive Method for Detecting Volatile Species in Liquids. Rev. Sci. Instrum. 2015, 86, 075006.

(46) Trimarco, D. B.; Scott, S. B.; Thilsted, A. H.; Pan, J. Y.; Pedersen, T.; Hansen, O.; Chorkendorff, I.; Vesborg, P. C. K. Enabling Real-Time Detection of Electrochemical Desorption Phenomena with Sub-Monolayer Sensitivity. Electrochim. Acta 2018, 268, 520-530.

(47) Łukaszewski, M.; Soszko, M.; Czerwiński, A. Electrochemical Methods of Real Surface Area Determination of Noble Metal Electrodes-an Overview. Int. J. Electrochem. Sci. 2016, 11, 44424469.

(48) Holby, E. F.; Sheng, W.; Shao-Horn, Y.; Morgan, D. Pt Nanoparticle Stability in PEM Fuel Cells: Influence of Particle Size Distribution and Crossover Hydrogen. Energy Environ. Sci. 2009, 2, 865-871.

(49) Hengge, K.; Gänsler, T.; Pizzutilo, E.; Heinzl, C.; Beetz, M.; Mayrhofer, K. J. J.; Scheu, C. Accelerated Fuel Cell Tests of Anodic $\mathrm{Pt} / \mathrm{Ru}$ Catalyst via Identical Location TEM: New Aspects of Degradation Behavior. Int. J. Hydrogen Energy 2017, 42, 2535925371. 